\title{
Internalization of Race Messages Among Mixed Race Individuals
}

Jennifer Moulton

Loyola University Chicago

Follow this and additional works at: https://ecommons.luc.edu/luc_diss

Part of the Psychology Commons

\section{Recommended Citation}

Moulton, Jennifer, "Internalization of Race Messages Among Mixed Race Individuals" (2014).

Dissertations. 1292.

https://ecommons.luc.edu/luc_diss/1292

This Dissertation is brought to you for free and open access by the Theses and Dissertations at Loyola eCommons. It has been accepted for inclusion in Dissertations by an authorized administrator of Loyola eCommons. For more information, please contact ecommons@luc.edu. (c) $($ ) $\Theta \Theta$

This work is licensed under a Creative Commons Attribution-Noncommercial-No Derivative Works 3.0 License. Copyright $\odot 2014$ Jennifer Moulton 
LOYOLA UNIVERSITY CHICAGO

THE INTERNALIZATION OF RACE MESSAGE AMONG MIXED RACE INDIVIDUALS

A DISSERTATION SUBMITTED TO

THE FACULTY OF THE GRADUATE SCHOOL

IN CANDIDACY FOR THE DEGREE OF DOCTOR OF PHILOSOPHY

PROGRAM IN COUNSELING PSYCHOLOGY

\author{
BY \\ JENNIFER MOULTON \\ CHICAGO, ILLINOIS \\ DECEMBER 2014
}


Copyright by Jennifer Moulton, 2014 All rights reserved. 


\section{TABLE OF CONTENTS}

LIST OF TABLES $\quad$ v

$\begin{array}{lr}\text { ABSTRACT } & \text { vi } \\ \text { CHAPTER ONE: INTRODUCTION } & 1 \\ \text { Racial Socialization } & 2 \\ \text { Racial Identity Development Models } & 4 \\ \text { Grounded Theory } & 9 \\ \text { Purpose } & 10 \\ & \\ \text { CHAPTER TWO: REVIEW OF LITERATURE } & 12 \\ \text { Historical Contexts } & 12 \\ \text { Early Laws Concerning Interracial Relationships } & 12 \\ \text { Scientific Discourse on Racial Mixture } & 13 \\ \text { Current Mixed Race Research } & 18 \\ \text { Racial Identity Development Models } & 18 \\ \text { Factors Influencing Mixed Race Identity Development } & 26 \\ \text { Summary } & 32\end{array}$

CHAPTER THREE: METHODS

Participants $\quad 34$

$\begin{array}{ll}\text { Procedures } & 35\end{array}$

Data Analytic Procedures $\quad 36$

Open Coding $\quad 37$

Axial Coding 37

Selective Coding $\quad 38$

Researcher Background, Experiences and Biases 38

CHAPTER FOUR: RESULTS 41

Racial Socialization Contexts $\quad 42$

Family $\quad 43$

Friends $\quad 49$

Community $\quad 51$

Society $\quad 56$

Racial Messages $\quad 59$

Belonging $\quad 59$

$\begin{array}{ll}\text { Racial Physical Features } & 62\end{array}$

$\begin{array}{ll}\text { Racial Jokes and Teasing } & 64\end{array}$

Racism $\quad 65$

Impact of Race Messages $\quad 67$

Message Influence on Understanding of Race $\quad 67$

Message Influence on Racial Identification $\quad 74$ 
$\begin{array}{ll}\text { CHAPTER FIVE: DISCUSSION } & 78\end{array}$

Implications $\quad 83$

$\begin{array}{ll}\text { Racial Identity Development Theory } & 83\end{array}$

$\begin{array}{ll}\text { Research } & 84\end{array}$

$\begin{array}{ll}\text { Clinical Practice } & 85\end{array}$

Prevention $\quad 86$

Limitations and Future Directions

$\begin{array}{lr}\text { Conclusion } & 89\end{array}$

APPENDIX A: DEMOGRAPHIC FORM

APPENDIX B: INTERVIEW QUESTIONS 94

$\begin{array}{ll}\text { REFERENCE LIST } & 97\end{array}$

$\begin{array}{ll}\text { VITA } & 102\end{array}$ 


\section{LIST OF TABLES}

Table 1. Demographic Information of Participants 42

Table 2. Racial Socialization Contexts: Emergent Themes and Frequencies 43

Table 3. Race Messages: Emergent Themes and Frequencies 59

Table 4. Message Influence of Understanding of Race: Emergent Themes and Frequencies 


\begin{abstract}
The present study used grounded theory qualitative methodology to explore mixed race individuals' experiences within specific racial socialization contexts of family, friends, community, and society, to identify messages received within these contexts. How messages influence both their understandings of mixed race identity and how they racially identify themselves was also examined. Mixed race identity development was found to follow an ecological framework, in which racial socialization messages serve as a mechanism through which experiences within contexts may be interpreted, to then inform conceptions of racial identity and identification choices. Common themes of experiences emerged within contexts, including disownments/disapproval, sibling differences, race dialogues, seeking diversity and racial awareness, community racial dynamics, 'What are you?' questions, racial categorization, normativity, attractiveness, and the President Obama effect. Additionally, general message themes of belonging, racial physical features, racial teasing, and racism, emerged across these contexts. Messages influenced understandings of mixed race identity through the cultural consciousness, racial discourse, pride, and awareness of mixed race privilege. While personal racial identifications varied, messages influenced conscious decisions in identifying to others as mixed, rather than choose one race over the other.
\end{abstract}




\section{CHAPTER ONE \\ INTRODUCTION}

As society has become increasingly diverse and accepting of the similarities and differences among various racial groups, one group remains largely in the margins of racial awareness and understanding- people of mixed racial descent. As the product of two or more racial groups, they represent the blending of the color lines; to some, they highlight the notion that race is a social construct, and to others, they symbolize the depurification of races that are meant to remain separate (Edwards \& Teramoto Pedrotti, 2008; Dalmage, 2004; Ferber, 2004; Teo, 2004; Tucker, 2004; Root, 1992; Wardle 1996). They are a minority group that is frequently considered to have an ambiguous racial identity and racial affiliation as experienced by the members of this group. Furthermore, society has commonly perceived them as an anomaly, because they are unable to be categorized in a singular way (Confresi, 2006; Collins, 2000; Miville, Constantine, Baysdon, \& So-Lloyd, 2005; Root 1992, 1998). While these sentiments may not be true for all, mixed race individuals are often conceptualized as a confusing/confused group that should be studied to clarify the role of race among people who have more than one.

Throughout the course of history in the United States, mixed race individuals have been defined and described by individuals other than themselves (Christianson, 2000; McClain DaCosta; 2004; Nakashima, 1992). Within the social sciences, conceptualizations of mixed race people have shifted from notions of biological impurity 
and weakness, to psychological maladjustment, to sociopolitical arguments. For example, in sociopolitical contexts it has been suggested that "intermarriage and multiracial people represent the loss or the 'dilution' of distinct ethnic and racial groups; and mixed-race people and their families have dubious political and social loyalties" (Nakashima, 1992, p.165). These arguments have been used to justify the separation of races- such as through antimiscegenation laws- making interracial marriage illegal- that were in place until 1967, when in the case of Loving v. Virginia, the Supreme Court overturned interracial marriage bans in the 16 remaining states where such laws had been in effect (Brown, 1995; Kerwin \& Ponterotto, 1995; McClain DaCosta, 2004; Root, 1992; 1998; Tucker, 2004); although unenforceable, a prohibitive clause remained in the South Carolina State Constitution until 1998, and a ban on interracial marriage remained in the Alabama State Constitution until 2000 (Patria, 2007). As such, these have served to influence complicated notions of the meaning of race for individuals with mixed racial backgrounds. The present study intends to examine how mixed race individuals make their own meaning of their racial backgrounds, as influenced by the messages they have received regarding race and mixed race identity.

\section{Racial Socialization}

"Racial socialization consists of the mechanisms through which parents transmit information, values, and perspectives about race and ethnicity to their children" (Seaton, Yip, Morgan-Lopez, \& Sellers, 2012, p. 450). Seaton et al. (2012) suggest that racial socialization influences racial identity development through instilling pride and knowledge of one's own group affiliation. Racial socialization is also a means of preparing young people of color for potential harassment, discrimination, or racist 
encounters (Bynum, Burton, \& Best, 2007; Fisher \& Shaw, 1999; Wills et al., 2007). Messages are additionally communicated regarding the significance and meaning of race, racial status, and social stigma (Smalls; 2010), as well as cultural attitudes, beliefs, and behaviors (Robbins, Szapocznik, Mayorga, Dillon, Burns \& Feaster, 2007). Furthermore, racial socialization messages may be received explicitly through direct communication about racial issues, as well as implicitly through indirect messages about race (Stevenson \& Renard, 1992), such as through hearing and observing racial assumptions, stereotypes, and microaggressions.

Research on racial socialization has focused primarily on processes for African Americans (Brody et al., 2006; Bynum, Burton, \& Best, 2007; Fisher \& Shaw, 1999; Lalonde, Jones, Stroink; 2008; O’Brien Caughy, O’Campo, \& Muntaner, 2004; Robbins et al., 2007; Smalls, 2010; Stevenson \& Renard, 1993; White-Johnson, Ford, \& Sellers; 2010; Wills et al., 2007), with no specific studies having been conducted on the racial socialization process of mixed race individuals. Additionally, most of the existing literature has focused on socialization messages from parents and family (Brody et al., 2006; Bynum et al., 2007; Fischer \& Shaw, 1999; Hughes et al., 2006; O’Brien Caughy, 2004; Robbins et al., 2007; Rodriguez, Umaña-Taylor, Phillips Smith, \& Johnson, 2009; Smalls, 2010; Stevenson \& Renard, 1993; White-Johnson et al., 2010; Wills et al., 2007), with particular emphasis on racial socialization as a means of preparing children of color for experiences of discrimination and racism (Bynum, Burton, \& Best, 2007; Fisher \& Shaw, 1999; Wills et al., 2007).

While it may be well supported that family, and parents in particular, may serve as the primary source of racial socialization, individuals may additionally receive racial 
socialization messages from friends and peers, communities in which one lives, and from societal sources, such as news and popular media (Seaton et al., 2012). To date, there has been minimal exploration of friend and peer, environment/community, and societal socialization messages, and how those impact racial socialization processes. While it is acknowledged that racial socialization messages are received both explicitly and implicitly, the research has namely examined explicit forms of socialization. In their 1999 study, Fischer and Shaw recommended that additional research on the mechanisms by which messages are sent, received, processed, and internalized would be beneficial; to date such research has yet to be conducted concerning mixed race individuals. The present study aims to address these gaps in the existing racial socialization literature by examining the race messages that mixed race individuals receive from different sources, how they make sense of those messages, and how those messages may be internalized in how they racially identify themselves.

\section{Racial Identity Development Models}

Within the social sciences, racial identity models have been researched and developed for people of distinct monoracial groups (Cross, 1971; Ruiz, 1990; Sue \& Sue, 1971), with stages of gaining understanding, awareness, and coming to integrate racial concepts into a person's identity. The implications of these models for mixed race people are less clear. Cross (1971) developed a model of African American identity development that included the following stages: pre-encounter, encounter, immersion/emersion, internalization, and internalization/commitment. Subsequent models of identity development for different racial groups have been developed (Ruiz, 1990; Sue \& Sue, 1971), and all seem to propose equivalent stages to those described by Cross (1971). As 
people of color move through these stages they are at first unaware of the impact of racism in their lives and hold views that are in line with that of dominant- White- society (Cross, 1971; Ruiz, 1990; Sue \& Sue, 1971). They then experience an event, or series of events, that brings the impact of racism to their awareness. Individuals then immerse themselves within their racial group and attempt to avoid or reject White influences by seeking out opportunities to examine their culture and history, and affiliate themselves with others of their own racial group. Through this process of self-exploration, individuals develop a sense of security in their racial identity and the need to avoid dominant influences dissipates. They then become more open to establishing relationships with White individuals while maintaining close ties to individuals of their own racial group. People develop a positive sense of racial identity and become committed to take action to meet the concerns of their racial group in a proactive way.

While a few models of biracial identity development have been created (Jacobs, 1992; Kerwin \& Ponterotto, 1995; Kich, 1992; Poston, 1990; Root, 1998), Poston’s (1990) model is the most commonly referenced. Poston (1990; Kerwin \& Pontorotto, 1995; Collins, 2000; Miville et al., 2005; Edwards \& Teramoto Pedrotti, 2008) argued that monoracial identity development models are poorly fit for biracial individuals for the following reasons: (a) monoracial models for people of color involve a stage of rejecting their minority status to identify with majority culture, (b) they exclude the possibility for an integrated racial identity, and (c) they assume when individuals immerse themselves in their minority culture, the minority community will accept them (Root, 1998). Additionally, monoracial models overlook the possibility that mixed race people may identify with one group over another at different points in life (Miville et al., 2005; Shih 
et al., 2007). Poston (1990) proposed a five stage model in which young persons move from (a) having no group affiliation, to (b) feeling pressure to choose a group to identify with, to (c) feeling guilt, confusion and/or self-hatred for choosing a group that may reject them or suggests disloyalty to one parent, to (d) appreciating their multiple heritages, and lastly, (e) developing an integrated identity. The implication of this model is that all mixed race individuals go through the same process and that an integrated racial identity is optimal. This suggests further that individuals who identify otherwise may not have a healthy racial identity. How mixed race persons may interpret this message and how it applies to them may bear implications for how they come to understand their own racial identity.

Despite attempts to create models for biracial and multiracial identity development (Jacobs, 1992; Kich, 1992; Kerwin \& Ponterotto; 1995; Poston, 1990), the identified stages are not necessarily universal. Kerwin and Ponterotto (1995) suggested that personal, societal and environmental factors influence a person's progression through stages of mixed race identity formation during developmental stages of life, from preschool to adulthood. They argue further that while there may be commonalities across these stages, how one comes to a resolution of their identity- or how they come to identify themselves- is a personal process. These researchers suggested the need for further examination of how mixed race individuals may be influenced by messages from people in their life, such as family and peers, as well as environment, in developing a healthy sense of identity (Kerwin \& Ponterotto, 1995).

It has been found that family, social relationships, environment, experiences of racism, and a vast assortment of other factors can all play significant roles in informing 
and shaping how a mixed race individual comes to identify themselves racially (Kerwin \& Ponterotto, 1995; Kerwin, Ponterotto, Jackson, \& Harris, 1993; Miville et al., 2005; Root, 1998; Suzuki-Crumly \& Hyers, 2004). Furthermore, mixed race individuals identify themselves in different ways, such as biracial, multiracial, interracial, mixed, and some identify with one race (Brown, 1995; Kerwin \& Ponterotto, 1995; Root, 1998; Suzuki-Crumly \& Hyers, 2004), and that identification may change in different private and public contexts (Ahnallen, Suyemoto, \& Carter, 2006; Brown, 1995; Miville et al., 2005; Root, 2002; Shih, Sanchez, Bonam, \& Peck, 2007).

The variety and fluidity of racial identification among mixed race individuals may be accounted for by Root's (1998) ecological model of racial identity development. This model identifies numerous factors, such as gender, regional history of race relations, inherited influences, personal traits, etc., which may interact in a variety of ways to influence how one may racially identify themselves. Root (1998) suggested that this model could explain how siblings, growing up in the same family and in similar contexts may racially identify themselves differently from one another. Root (1998) described her study as a "preliminary discussion of the findings of the process affecting identity development that appear to account for some differential choices within the same family" (p. 238). Despite the suggestion that her model was only preliminary in accounting for variability in racial identification, research has yet to test this model further and examine more deeply how the interaction of the various factors identified in this model may inform and influence racial identification. Direct and indirect racial socialization messages may be communicated from different sources, and how one makes sense of those may impact racial identity. The present study intends to take a closer look at how 
race messages may serve as a potential mechanism through which meaning about race and racial identity may be derived from different socialization contexts, to inform racial identity development.

Historically, society has generally categorized mixed race people according to the race they most physically resemble rather than categorizing according to personal racial identification (i.e.- President Barack Obama identified as the first Black president). Much of the literature minimizes the extent to which this occurrence may affect how mixed race individuals may come to identify themselves racially. With the changing social landscapes and understanding of racial dynamics, the conversations on race are advancing and warrant additional examination, particularly when it comes to mixed race individuals. Furthermore, there is lack of acknowledgment of how the messages mixed race individuals receive about their heritage- being un-pure, anomalous, psychologically maladjusted - may influence and shape the way they understand the concept of race and their racial identity (Collins, 2000; Miville, Constantine, Baysdon, \& So-Lloyd, 2005; Root, 1992; 1998; Teo, 2004; Tucker, 2004; Wardle 1996). The existing racial identity development models for mixed race individuals do not account for racial socialization messages that may be received from different sources, how these may influence the progression through stages of identity development, nor how messages may inform one's sense of racial identity. Furthermore, more often than not, research concerning this population is examined through the eyes of the researchers who continue to categorize and conceptualize mixed race individuals through their own view, rather than giving voice to those being studied. Therefore, this study proposes to give voice to this 
population through the use of grounded theory, qualitative methodology in examining mixed racial individuals' racial identity formation experiences.

\section{Grounded Theory}

In an effort to allow the voices of mixed race individuals to be heard over the voices of researchers and to permit them to speak for themselves about their racial identities, grounded theory qualitative methods will be used for the present study. Grounded theory provides a frame for the themes and concepts to emerge from the stories being told with little imposition of researchers' personal perspectives, biases, or hypotheses leading the data (Merriam, 2009). As such, a theory may be developed as it arises from, or is grounded in, the collected data. To date, within the Counseling Psychology literature, five qualitative studies have been published examining racial identity development among mixed race individuals (Collins, 2000; Jourdan, 2006; Kerwin et al., 1993; Miville, Constantine, Baysdon, \& So-Lloyd, 2005; Root, 1998), utilizing ethnographic, narrative, and phenomenological methods. These studies highlight shared themes and common experiences among mixed race individuals, such as fluidity in racial identification, encounters with racism, and experiences within specific contexts of family, social relationships, and environment in influencing individuals' understanding of their racial identity. While previous literature has suggested that messages regarding race are communicated within socialization contexts of family, friends, community, and society, these studies have lacked exploration of how and what messages are communicated within these contexts. The intention of the present study is to expand upon previous research by examining mixed race individuals' experiences and the racial socialization messages they receive, within specific contexts of their lives, and 
developing a theory of how these experiences and messages relate to and inform racial identity development among mixed racial individuals.

Merriam (2009) suggests that unlike other methods of qualitative research, a grounded theory approach is focused on building a theory that is "substantive rather than formal or grand" (p. 30); meaning that every-day world situations are the main referent in building a theory, such as making sense of messages regarding race. Furthermore, grounded theory has been recommended for examining questions regarding process, or how things change and/or develop over time. In utilizing a grounded theory qualitative approach, this study will address aspects of the process of racial identity development in mixed race individuals and provide them with an opportunity to examine their own personal definitions and understanding of their racial identity. They will also be given space to discuss their experiences in receiving messages regarding race from various sources, from their close relationships to society at large, thereby bringing in participants', as opposed to researchers', aspects that have been mostly missing from the present research concerning mixed race individuals.

\section{Purpose}

This study proposes to add to the literature on biracial/multiracial identity by qualitatively exploring how mixed race individuals process the often varied and confusing messages they receive about race from family, peers, their community, and society as a whole. Specifically, this study seeks to examine the following research questions:

1) What messages, if any, do mixed race individuals receive regarding race and mixed racial identity? 
2) Do these messages become internalized and possibly incorporated into mixed race individuals' understanding of their own racial identity and influence how they come to identify themselves racially. If so, in what ways?

This study will be an important contribution to the field of Counseling Psychology, as it may provide implications for working with mixed race individuals who may present for counseling with issues related to dealing with society's reactions to their racially mixed heritage (Edwards \& Teramoto Pedrotti, 2008). It may also elucidate specific processes by which messages are internalized, thereby opening areas for additional study. The next chapter will discuss historical perspectives and the current literature on biracial and multiracial identity, as well as present methods for conducting the proposed study. Throughout this proposal, the terms 'mixed race', 'biracial', and 'multiracial' will be used to describe individuals of mixed racial descent. The study will namely refer to these individuals as 'mixed race', since biracial and multiracial denote racial identities that not all participants in this study may identify with, whereas mixed race references heritage and allows subjects to identify themselves as they seem fit. 


\section{CHAPTER TWO \\ REVIEW OF LITERATURE \\ Historical Contexts}

\section{Early Laws Concerning Interracial Relationships}

In order to adequately understand racial identity of mixed race individuals and the racial messages that pertain to this group, one must take into account historical contexts and perspectives that have influenced both the experiences of mixed race individuals, as well as how they have been conceptualized and understood in research. The mixing of races has long been considered a problem to be guarded against, with different races remaining separate to maintain the purity of society (Ferber, 2004; Teo, 2004). In the 1600 s, as concerns arose about interactions between slaves and slave owners, legal debates and the creation of laws against interracial marriage and sex began in the United States (Ferber, 2004; Nakashima, 1992; Teo, 2004; Tucker, 2004). These laws were concerned only with unions between Whites and non-Whites, and not with unions between two racially non-White individuals; this is an indication that the primary purpose of these laws was to keep Whites separate from all other racial groups (Kerwin \& Ponterotto, 1995; McClain DaCosta, 2004; Daniel, 1992). In 1661, a Maryland statute declared that a free woman who married a slave would become enslaved herself, as well as any children born of that union (Tucker, 2004). Some slave owners, in an attempt to 
increase their slave holdings, encouraged White women marrying their Black servants. This led to an amendment to the statute in 1681 which penalized this practice by requiring slave owners to financially provide for the children born of these marriages. The burden of these financial costs influenced the prohibition by law of all marriages between White and Black individuals, and other states soon implemented similar laws.

\section{Scientific Discourse on Racial Mixture}

Biological arguments. Teo (2004) noted that various scientific fields have "participated in and promoted a discourse in which race crossing was constructed as an unnatural process leading to the decline in culture, intellect, and personality" (p. 80). The sciences have promoted the notion of hybrid degeneracy, in which the mixing of races decreases the biological superiority of the White race; This has served to provide justification for preventing interracial unions and conceptualizing children produced from those unions as impure and of lesser value to society (Ferber, 2004; McClain DaCosta, 2004; Nakashima, 1992; Teo, 2004; Tucker, 2004). Within the medical community, numerous doctors argued that offspring of intermarriage were susceptible to disease and infertility. It was also suggested that mixed children displayed a lack of strength and endurance, and if mixed breeds were to continue to intermarry, they would die out within a few generations. It was stated further that the existence of a hybrid race would lead to the deterioration of the United States from the disease and sterility they carried. Labeling mixed race people as diseased made it reasonable to put restrictions on intermarriage and keep different races separate and pure (Ferber, 2004; Nakashima, 1992; Teo, 2004). Spickard (1992) suggests that the most important factor in constructing notions about races, was the boundaries placed between them. Therefore, the maintenance of 
boundaries that delineated racial hierarchies with Whites at the top and Blacks on the bottom, was essential to keep one race superior and lower races from moving upward or bringing down White society.

Consequently, in accordance with the U.S. laws of hypodescent which formed the basis of the one drop rule, an individual who had any Black blood in their heritage would be categorized as Black, even if they had no discernible Black features (Brown, 1995; Daniel, 1992; Gillem, Cohn, \& Throne, 2001; Kerwin et al., 1993; McClain DaCosta, 2004; Miville et al. 2005; Root, 1998; Spickard, 1992; Suzuki-Crumly \& Hyers, 2004). Such categorization served to protect and uphold White dominance, by assigning people of mixed descent to a lower racial social status, and denying individuals with any traceable Black heritage access to economic and political control allotted to White people with no trace of Black blood (McClain DaCosta; 2004; Miller, 1992; Root, 2002). Terms were developed by human scientists and politicians to categorize Black/White offspring, such as quadroon, octoroon, and sambo for individuals who were three parts White, seven parts White, and three parts Black, respectively (Teo, 2004). In creating labels based on percentages of Whiteness and Blackness, divisions between more and less pure races could be maintained, and accountability of White men who had raped Black women to provide for the offspring of these rapes could be withheld, by drawing a line between White and Black. While these exact labels may not persist today, the implications of ideas of purity for mixed race people do.

Spickard (1992) argued that during the process of racial labeling "a group is defined by an observer according to its location, its cultural practices, or its social connectedness (and their subsequent economic, social, and political implications)" (p. 
16). It is suggested that race is a social construct that can be constructed differently according to time and place with change in social situations (Ferber, 2004; McClain DaCosta, 2004; Spickard, 1992). For instance, when different racial groups come into competition for status or economical gain, racial stratification occurs, with one racial group holding domination over another. As a way of ignoring individual humanity and lessening any feelings of guilt over the act of oppression, the dominant group may create negative myths about the subordinate group's moral qualities (Ferber, 2004; Spickard, 1992). In this way, slave holders could justify within themselves owning slaves and treating them poorly by attaching ideas of evil, sin, and laziness with the Black racial group. These ideas then serve to influence social feelings and attitudes about racial mixture, because they imply that if a White person, who is perceived as good and pure, were to have a child with a Black person, who is labeled as evil, that child will have potential for evil and sin, and therefore prevention of such births would be justified.

Psychological arguments. During World War II a shift in the conceptualization of mixed race people occurred, in which biological problems were de-emphasized, and notions of psychological maladjustment were more commonly explored (Teo, 2004). The idea of the 'marginal man' became popularized, in which a mixed race individual was considered on the margins of society, unable to cope with their biculturality and lack of ability to be a true member of either racial group in their background (Kerwin \& Ponterotto, 1995; Nakashima, 1992; Teo, 2004; Spickard, 1992; Stonequist, 1937). By virtue of their marginal status, as opposed to their biology, mixed people were considered socially inferior. They were conceived as being psychologically damaged by their inability to make sense of themselves as two disparate races, and potentially dangerous 
through their ability to possibly pass as Caucasian and maneuver in White society. If a mixed race person can pass themselves off as White and operate from a White reference group, they thereby have the potential to upset the balance of the power structure of White domination.

Socio-political arguments. Antimiscegenation laws had been repealed in many Northern states during the $19^{\text {th }}$ century, but remained in place in the South with prison sentences of up to 10 years in prison if violated (Tucker, 2004). By the time of the Civil Rights Movement, 16 states still had these laws in effect until 1967 when the U.S. Supreme Court ruled in the case of Loving vs. Virginia that banning interracial marriage was unconstitutional and it would no longer be illegal to marry outside of one's racial group (Brown, 1995; Kerwin \& Ponterotto, 1995; McClain DaCosta, 2004; Root, 1992; 1998; Tucker, 2004). This opened the doors for individuals of different races to come together and spurred what Root $(1992 ; 1998)$ termed the "biracial baby boom." Furthermore, it became more widely acknowledged that most people of color were in some way mixed, that that could be a positive, as opposed to marginalizing, experience, and mixed race people could potentially bridge racial divides (Nakashima, 1992).

Granted, another product of the Civil Rights Movement was an increased notion of racial solidarity, and a shift from the "melting pot" idea of America to the "salad bowl" in which different races exist together as opposed to melting together. This once again gave little room for acceptance of mixed race people, because they represented the blending of the color lines. Nakashima (1992) suggests that, during this time, discussions of mixed race people shifted from notions of biological impurity and weakness, and psychological maladjustment, to sociopolitical arguments, such as 
people of color who marry Whites are trying to 'raise' themselves economically, socially, and racially; intermarriage and multiracial people represent the loss or the 'dilution' of distinct ethnic and racial groups; and mixedrace people and their families have dubious political and social loyalties (p.165).

These arguments were made by both White people and people of color, who felt that people who marry White people are "sellouts" or traitors to their race (Daniel, 1992; Ferber, 2004; Nakashima, 1992), and mixed offspring should only identify with their minority race, in order to maintain minority numbers and political influence (McClain DaCosta, 2004; Shih, Sanchez, Bonam, \& Peck, 2007). As a result, mixed race people who were part White were considered to have questionable racial loyalties, due to the actions of their parents (McClain DaCosta, 2004; Ferber, 2004; Brown, 1995).

Nakashima (1992) argues that mixed people have historically been defined by others, placed in the monoracial system operating in the U.S., from which they may internalize confusing images of themselves, feel as if they fit nowhere, or attempt to deny their mixed heritage. Estimates of the number of mixed race people living in the U.S. revealed growth in their population from 46,000 in 1970 to approximately 996,070 in 1980, and rose to about 2 million in 1990 (Ahnallen, Suyemoto, \& Carter, 2006). It wasn't until 2000, that individuals were allowed to identify themselves as being more than one race on the U.S. national census (Miville et al., 2005; Root, 2002; SuzukiCrumly \& Hyers, 2004), at which point $2.4 \%$, or 6.8 million people, of the U.S. population used that option (U.S. Bureau of the Census, 2001). Prior to that, individuals were forced to choose one race, which would more often be as a person of color, continuing with the notion of the one drop rule. More individuals are beginning to identify themselves as mixed, but the remnants of the past still operate in today's system 
of race, and mixed race people continue to be defined and categorized in research in ways that may not be in accordance with their personal definitions of a racial self.

\section{Current Mixed Race Research}

The majority of current research concerning mixed race individuals focuses on unraveling the dimensions involved in racial identity development among these individuals and how they come to identify themselves in racial terms, namely, whether they identify with one race or as biracial/multiracial. The studies debate the values of having an integrated versus a monoracial identity, with most viewing an integrated racial identity as most beneficial. There is consensus that racial identification is a process and that as individuals grow older, their identities become more defined. Some studies lay out this process in terms of linear stages, while others discuss multiple factors that shape racial identity over time, such as family, environment, socialization, experiences with racism, and personal identification of race.

\section{Racial Identity Development Models}

Stage theory model of biracial identity development. As mentioned in chapter one, a few models of biracial/multiracial identity development have been created (Jacobs, 1992; Kerwin \& Ponterotto, 1995; Kich, 1992; Poston, 1990). Poston's (1990) model is the most commonly referenced in this area of study. He proposed a five stage model that begins with the personal identity stage, in which a young person has yet to identify themselves with a reference group, and views themselves as separate. The second stage, involves the individual feeling pressured to choose a group to identify with. The choice is usually influenced by personal, social, and environmental factors. The third stage, which Poston (1990) termed the enmeshment/denial stage, the individual begins to have feelings 
of confusion, guilt, and/or self-hatred associated with having to choose a group, possibly due to feelings of rejection from the group they chose and disloyalty to one parent. During the fourth stage, appreciation, the individual comes to accept and appreciate their multiple heritages and attempts to learn more about both backgrounds. Integration is the final stage in which the individual embraces being biracial and experiences a sense of wholeness in their racial identity. The implication of this model is that all mixed race individuals go through the same process and that an integrated racial identity is optimal. This suggests further that individuals who identify otherwise may not have a healthy racial identity. How a mixed race person may interpret this message and how it applies to him or her may bear implications for how they come to understand their own racial identity.

Jacobs (1992) conducted a study in which Black/White biracial children ages 3-12 were given doll-play tasks, using dolls that ranged in skin and hair color from dark to light, size to represent an adult, child, and baby, and some dolls contained Asian features to give children the opportunity to demonstrate an understanding of concepts that classified individuals who were outside of the Black/White spectrum. Children were also interviewed concerning their choices in dolls for each task. Tasks included such activities as choosing a doll that the child thought looked most like them, picking out dolls that made up a family like their own, selecting dolls that they would like or dislike playing with, and which doll they thought they would look like when they grew up. The children were then asked to explain their choices.

Drawing upon the results of this study, Jacobs (1992; Kerwin \& Ponterotto, 1995; Collins, 2000) proposed a three-stage model for biracial identity development. During the 
first stage, pre-color constancy, children tend to accurately identify the doll that most closely represents them in skin color, but their concept of color tends to be nonevaluative, and children make flexible choices in dolls representing their family members. Jacobs (1992) suggests that, "color constancy has not been attained, so color can be explored with no firm classification into social groups by race” (p. 200). He argues further, that children who do not explore play with other colored dolls may have low self-esteem and/or have had painful experiences with race or racial prejudice.

The next stage, post-color constancy, tends to be reached by age $41 / 2$. During this stage, the child has a better understanding of the meaning of color, a generally firm notion that their skin color will not change, and develop ambivalence about their own racial status. Children in the study commonly showed a preference for the White dolls and rejected the Black dolls, demonstrating an awareness of social discrimination based on color. Jacobs (1992; Kerwin \& Ponterotto, 1995) argued that this stage of ambivalence was necessary in order for children to reconcile discordant elements of their identity and develop a unified understanding of self, through internalization of a biracial label for themselves. He notes that the biracial label tends to be presented initially to the child by their parents, and they come to incorporate that label into their self-concept, thereby laying the foundation to construct their racial identity. The third stage, biracial identity, takes place between 8 and 12 years of age, during which time the child comes to understand that racial group membership is determined by their parentage and not necessarily their skin color, despite the fact that their skin color may be correlated with their racial group membership. The child's ambivalence towards race decreases and they begin to identify themselves as biracial, not solely based on the color of their skin, but 
because one parent belongs to the social group of Black people and the other belongs to the social group of White people.

Kich (1992; Collins, 2000, Kerwin \& Ponterotto, 1995) also developed a three stage theory of biracial identity development, based on content analysis of semistructured interviews conducted with 15 biracial White/Asian individuals, ages 17-60. The interviews provided participants' personal information and history, and explored emergent themes of an evolving sense of self and the process of resolving their biracial identity. Kich (1992) suggests that individuals experience "transitions from a questionable, sometimes devalued sense of self to one where an interracial selfconception is highly valued and secure" (p. 305). During the initial stage, taking place between ages 3 through 10, the individual gains an awareness of their differentness, as being both Asian and White, yet are not fully either race, and experience a dissonance between their self-perceptions and the perceptions others have of them. This dissonance acts as a catalyst for the second stage, struggle for acceptance, beginning at age eight and lasts through adolescence and young adulthood. During this stage the individual's experience of differentness is heightened as they try to forge friendships and become increasingly aware of how others see them and their families. They are often asked to explain their heritage to others and respond to questions such as "What are you?" (p. 309). From late adolescence through adulthood, the individual goes through the third stage of self-acceptance and assertion of an interracial identity. During this stage the individual forms a stable acceptance of self as biracial and bicultural. Kich (1992) notes that a biracial person's ability to gain self-acceptance is influenced by their attempts for other-acceptance, but that may never be fully achieved, so the individual must create a 
self-definition that is not based on that of others. Furthermore, a biracial individual comes to value their identity as something that is constructed from the relationships between personal and social meanings of race and group membership.

Kerwin and Ponterotto (1995) proposed a model for biracial identity development that integrated findings of earlier proposed models with the findings of studies by Kerwin (1991) and Kerwin et al. (1993). Their model attempted to capture variability in identity development processes that influence differences in racial identification (i.e.- a person having a different public racial identification and private racial self-concept), while maintaining a stage model format. They argued that, "the steps toward biracial identity formation is dependent on numerous personal, societal, and environmental factors. The actual resolution is also individual" (p. 210).

Kerwin and Ponterotto (1995) proposed a six stage model of racial identity development through which individuals progress over the lifespan from preschool to adulthood. They suggest that children first develop a sense of racial awareness between birth and the age of five years old; this occurs as they begin to notice differences in physical features, such as hair texture and skin color, of their parents and extended family members. Racial awareness may be further influenced by how sensitive and responsive parents may be in recognizing their children's awareness. Children may additionally be impacted by environmental factors, such as the racial heterogeneity or homogeneity of individuals they interact with in their daily lives, which may expose them to concepts of being a member of a minority or majority group.

The next stage occurs as children enter into school. It is suggested (Kattz, 1983, as cited in Kerwin \& Ponterotto, 1995) that children enter into school with defined 
notions about many social groups and characteristics that distinguish these groups. As they then enter school, children encounter questions of "What are you?", which come from a desire to classify and organize one's perceptual world in order to make it more simple to understand. Children respond to such inquiries with the labels and descriptive terms they use to understand themselves and their families. The types or labels and descriptors (i.e.- "biracial" versus "chocolate and vanilla") that they use are influenced by the degree to which their parents have discussed racial concepts and labels with them. Variability in the responses given by mixed race children to questions of identity classification, may also be influenced by how integrated their school environment is, and availability of role models they have from different racial groups.

As children enter into preadolescence, they gain increased recognition that differences in skin color and physical appearance are representative of group membership (Kerwin \& Ponterotto, 1995). This recognition is usually triggered by a specific event or environmental circumstances, such as experiencing their first encounter with racism. As such, they develop increased awareness of their own group membership and that of others, as represented by differences in skin color, language, and culture. Children begin labeling groups by social categories, such as by race or ethnicity, rather than descriptors of physical traits. Furthermore, they become aware that beyond differences in physical traits, their parents belong to distinct racial groups.

Kerwin and Ponterotto (1995) described adolescence as the most challenging stage for young mixed raced individuals, as they become faced with both common pressures of this developmental age group, and societal pressures. As adolescents are developing a sense of their personal identity and seek in-group membership, they may 
also experience pressures to identify with one group, thereby making conscious or unconscious choices to deny affiliation with one parent. Additionally, they may experience pressures to conform with societal expectations of identifying only with their parent of color. It is noted that this pressure may be mitigated to a certain degree by developing reference groups not connected to racial categories, such as participation on sports teams, clubs, or interest groups. Although, as adolescents begin dating, they may confront racial issues related to other's views on interracial dating.

As mixed race individual reach college age, or young adulthood, they may continue efforts to immerse themselves in one cultural identity, and rejecting the other (Kerwin \& Ponterotto, 1995). However, as they become more secure in their personal identity, they may become less influenced by the expectations of others on how to identify themselves. As such, this may influence greater acceptance of their mixed race heritage. They may also gain increased recognition of advantages and disadvantages of being mixed. Throughout their adulthood, mixed race individuals will continue to explore and integrate different aspects of their racial identity into their sense of self. Kerwin and Ponterotto (1995) argue that biracial identity development is a lifelong process, and that in adulthood an "integrated individual will find that he or she is able to function effectively in varying situations and understand different communities" (p.214). As a person explores their racial identity over their lifetime, they may experience increased flexibility in their relationships and broader understandings of others' cultures and their own.

Ecological model of racial identity development. Root (1998) proposed an ecological model of racial identity development in an effort to explain variability in racial 
identification amongst siblings. She argued that differences in racial identification amongst mixed race individuals, and even changes in identification over a lifetime, can be attributed to a variety of factors that do not necessarily reflect a linear stage process. Additionally, factors such as gender, regional history, personality traits, and situational contexts, can all play roles in experiences that inform racial identity, how one interprets those experiences, and how one copes or chooses to identify themselves. Root (1998) suggested that racial identity among mixed race individuals may be situational, simultaneous, changeable over the lifespan, and it may or may not coincide with how others racial identify them.

Root's (1998) model includes macro and micro lenses through which to view racial identity development processes. The macro-lenses include gender, social class, and regional history of race relations. She argued that these lenses "filter the meaning of situations and experiences to which people are exposed" (p. 238). Inherited influences, traits, and social environments then serve as micro-lenses. Inherited influences refer to biological and environmental factors that one is born into and are experienced in daily home life, such as given names, physical features, language(s) spoken at home, and cultural values. Traits are described as factors related to personality, such as temperament, special abilities or talents, and learned coping skills. Traits can influence how individuals, such as siblings, may respond differently to the same event or situation, and make different choices in their lives in response to similar circumstances. Social environments are the contexts in which individuals experience "social interactions in which the self is reflected" (Root, 1998, p.239); this includes home, school, and work environments. It is suggested that individuals may be treated similarly or differently in 
these environments, and can influence similar and disparate identities in different contexts. While it is not included as a macro or micro-lens, Root (1998) additionally highlights that generational differences may also inform racial identity development and identification.

\section{Factors Influencing Mixed Race Identity Development}

The role of family. Family, namely parents, are commonly noted as the most influential people in the development and understanding of a person's racial identity, as they are the primary providers of information and answers to their children's questions concerning race (Brody et al., 2006; Bynum et al., 2007; Fischer \& Shaw, 1999; Gillem, Cohn, \& Throne, 2001; Hughes et al., 2006; Kerwin et al., 1993; Kerwin \& Ponterotto, 1995; McClain DaCosta, 2004; Miville et al., 2005; O’Brien Caughy, 2004; Phillips Smith, \& Johnson, 2009; Robbins et al., 2007; Rodriguez, Umaña-Taylor, Smalls, 2010; Root, 1998; Stevenson \& Renard, 1993; White-Johnson et al., 2010; Wills et al., 2007). The messages that parents give to their children may influence mixed race individuals' identification with one race over the other, with their minority or dominant race parent (Gillem et al., 2001; Miville et al., 2005), an integrated identity (Kerwin et al., 1993; Miville et al., 2005), or may even create confusion in developing a racial identity (Gillem et al., 2001). Some research has suggested that parents are often aware that even if they encourage a biracial/multiracial identity for their children, there would be many instances in which a child may be asked to choose one race (Gillem et al., 2001; Kerwin et al., 1993). Therefore, how they discuss this occurrence with their children may be an important influence on how their children may racially identify themselves in those situations and in general. Furthermore, it was found that among parents of Black/White 
mixed children, Black parents tended to make more active attempts to discuss race with their children to prepare them for experiences with discrimination, than White parents. While both parents generally agreed on the importance of preparing their children for discrimination, Black parents felt it was necessary for their child's survival; it was suggested that Black parents felt a greater need for their children to identify as Black because society would categorize them as such (Gillem et al., 2001). Race may be a more salient topic of concern for Black parents because they have more experience than their White spouses of knowing what it is like to have their race work against them in terms of limited access to privileges allotted to White people, and therefore may have a different understanding of the implications that race may hold for their children. These findings suggest that it is important for parents to be clear on their own understanding of race and what it means to them, in order to provide their children with messages on the concept of race that support their children's search for meaning in having a racially mixed heritage.

The level of closeness that mixed race individuals have with their parents and extended family can play a major role in influencing the way these individuals come to resolve their racial identities (Gillem et al., 2001; Miville et al., 2005). Having a close relationship with family may lend itself to more open communication on race and identity that can assist an individual in resolving any conflicting feelings they may have in order to develop a secure racial identity, whereas a more distant relationship can influence confusion and painful feelings about their identity (Gillem et al., 2001). In addition to emotional closeness, Miville et al. (2005) noted that mixed race individuals may choose to identify with their parent of color, possibly due in part to experiences with monoracial 
racism- discussed below- which may increase the salience of messages they receive about being a person of color. Extended family members can also impart messages regarding race and racial identity through their ability to provide information about an individual's racial heritage, including cultural values, beliefs, and customs, and can provide individuals with guidance for coping with possibly conflicting cultural values, as they come to understand what it is to inherit the values of both races that make up their background (Miville et al., 2005).

Social relationships. Through the development of social relationships, racial differences are highlighted and mixed race individuals may seek out a reference group from which to understand themselves as racial beings (Miville et al., 2005). As mixed race individuals begin to form friendships and peer-groups, their awareness of their otherness becomes heightened, and they attempt to find a niche where they fit in. They start making observations of differences in their skin color and physical features from those of their peers, some may begin to affiliate more with other people of color, and as they get older, their identity may become more integrated (Miville et al., 2005). This process may be difficult, because unlike the racial identity development process of monoracial people during which an individual may immerse themselves in their racial reference group, mixed race people are not guaranteed acceptance by one or either racial group that they belong to (Ahnallen et al., 2006; Miville, 2005; Root, 1998; 2002).

Ahnallen et al. (2006) found that among White/Asian biracial people, the most significant factor influencing whether an individual racially identified themselves as White, Asian, or biracial, was the degree to which they felt excluded from one or more of these groups. These findings suggest that messages of belongingness and exclusion as individuals 
become socialized into various groups may have weight in how a person comes to racially identify themselves.

Experiences of racism. Considering the long history of prejudice towards mixed race people, only a few studies note experiences with racism in their conceptualization of biracial identity. Two common types of encounters with racism experienced by mixed individuals are monoracial racism in which individuals are targeted as a person of color (Miville et al., 2005), and multiracial racism in which individuals are faced with the common "What are you?" question (Kich, 1992; Kerwin et al., 1993; Kerwin \& Ponterotto, 1995; Miville et al., 2005) or prejudice for not fitting into one racial category. Miville et al., (2005) found that during encounters with monoracial racism, individuals experienced feelings of pain, shame, anger, and psychological distress. One Asian/White participant was quoted, "even though you're not 100\% Asian, you still get the stereotypes [about Asians]. You still get 100\% of the prejudice" (p. 510). This participant further commented that it didn't matter that he was half White, because society treated him as Asian, with all the stereotypes attached to that race.

Experiences with multiracial racism involve encountering numerous situations in which racist comments based on biracial individuals' ambiguous physical features and lack of clear indications of racial group membership were made (Miville et al., 2005). Mixed race individuals are often forced to explain their racial background to other individuals who struggle to categorize or classify them as a member of one racial group. As with encounters with monoracial racism, individuals may experience feelings of hurt and anger, but some learn to appreciate their unique appearance. Miville et al. (2005) note that multiracial racism is not limited to an individual level, but also occurs at the 
institutional level. Institutions frequently ask people to identify themselves, such as on school application, by choosing one race among the designated racial categories, which can be frustrating to individuals who identify with more than one race. One participant of Miville et al.'s (2005) study stated that he felt his racial status was more important to the institution than it was to him, and therefore the institution should choose what category he belonged in. Results such as these highlight messages received on multiple levels indicating a value placed on racial categorization and classification, and the frustration biracial people may experience in not fitting properly into monoracial systems. They may feel pressure to comply with institutions' expectations of how they should racially identify, which may not be in line with the way they personally prefer to identify themselves.

Environmental factors. Root (1998; 2002) suggests that geographic location plays a role in contextualizing the experience of race, for "location interacts with history and guides school, neighborhood, and community experiences of race" (Root, 2002, p. 183). Environmental make up and the history of race relations within a given city, town, or neighborhood influences the openness to racial diversity, feelings and perceptions concerning racial difference, and the presence of racial conflict within a given community (Kerwin et al., 2001; Miville et al., 2005; Root, 1998; Root, 2002). A mixed race person growing up in an environment that is open to diversity, may receive more encouraging messages on race and may be more supported in coming to understand their mixed heritage and developing a secure racial identity, whereas someone growing up in an environment that is largely racially segregated, may encounter more discrimination and lack of acceptance of the racial difference. 
Personal racial identification. Some studies have found that racial identification among biracial individuals can be rather fluid at times, in which individuals would identify themselves according to the setting or context they were in (Ahnallen et al., 2006; Brown, 1995; Kerwin, 1995; Miville et al., 2005; Root, 1998; Root, 2002; Shih et al., 2007). Miville et al. (2005) referred to this phenomenon as the "chameleon experience". Having flexible identity allows biracial individuals to adapt to cultural norms and demands in given situations, and provided flexible social attitudes to accept oneself and value similarities and differences of all people. Kerwin et al. (1993) found changing identification occurred with age; Young children tended to identify as biracial, mixed, or would report the races of their parents, but as they get older, they gain more racial awareness and may experience increased pressure to identify with one race.

A few researchers have noted that biracial individuals may identify themselves differently publicly, than how they identify themselves privately (Brown, 1995; Kerwin \& Ponterotto, 1995; Miville et al., 2005; Suzuki-Crumly \& Hyers, 2004). Brown (1995) found that among Black/White biracial individuals, "the compartmentalization into public and private identities seemed to help participants preserve their interracial self-perception while conforming to societal pressures to disregard their White roots" (p.127). Similarly, publicly identifying as a monoracial person of color, and privately identifying as biracial, can provide some individuals with a reference group and allowed them to find a sense of community and social support network among people who are similar to them (Miville et al., 2005). Suzuki-Crumly and Hyers (2004) suggest that due to the history of the onedrop rule forcing biracial Black/White people to identify as Black, they may feel that they are expected to identify more often with their Black heritage, as opposed to a White or a 
biracial identity. These scholars note further that the notion of having different public and private identifications may be different for biracial Asian/White individuals, because they can often "pass" as White, and historically, the one drop rule has been applied less rigidly to them. The majority of these individuals self-identified as biracial, followed by minority identification. These findings suggest that biracial people have an understanding of one of society's messages on race; they are expected to identify as one race, and more commonly identify in accordance with the physical traits that indicate minority group membership. Privately identifying as biracial may act as a form of resistance to that expectation and allows them to stay true to their personal connection to both of their racial backgrounds.

\section{Summary}

Throughout the history of the United States, there has been societal and social science interest in understanding the impacts of racial mixture. Research has been used to justify both the legal separation of races and disbandment of such laws as social views on race have changed over time. As interests in understanding racial identity development of mixed race individuals grew, models of these processes were proposed. In the twenty years since these models were originally developed, follow up studies to examine these models and test their validity have yet to be done. Additionally, these models lack exploration of how individuals progress through racial identity development stages, nor how meaning may be derived from contextual factors that influence identity development. Within research concerning influential factors, it is suggested that messages regarding racial identity are imparted, but no studies have specifically examined what messages are communicated or racial socialization processes of mixed race individuals. 
The present study intends to fill in these gaps in the current literature, by exploring how and what messages are communicated within different racial socialization contexts, and how these may inform and influence mixed race identity development. 


\section{CHAPTER THREE \\ METHODS \\ Participants}

Participants included individuals whose racial background was made up of at least two races. Participants were recruited from a large metropolitan city in the Midwest, and were contacted through organizations for mixed race individuals, such as the Biracial Family Network, through personal referrals (e.g., referrals from research team members and peers), and snowballing methods (e.g., asking participants for referrals to other mixed race friends or acquaintances). Participants were not required to personally racially identify in any particular way; for example, participants could identify themselves as biracial, mixed, interracial, multiracial, or as one race, as long as their parents each belong to different racial groups (e.g.,- Black and White, Asian and Black). While there was a degree of overlap, by having participants who did not all identify themselves in the same way, there was more variability of experience. This may be more representative (Heppner et al., 2008; Merriam, 2009) of the larger mixed race population in the United States, as opposed to only selecting individuals who identified themselves as biracial or as members of one race. Multi-ethnic individuals were excluded from the present sample, as the U.S. has a long history of divisions within society based on construct of race- for example, anti-miscegenation laws-, with lesser significance placed on ethnic groups 
(Edwards \& Teramoto Pedrotti, 2008; Teo, 2004; Tucker, 2004; Root, 1992; Wardle 1996).

While 13 participants were recruited for this study, 12 were included in the final sample due to poor sound quality on one recorded interview. The age range of participants was $18-44$, with an average age of 28 . The sample included six males and six females. The racial backgrounds of participants included seven individuals who were Black and White, three who were Asian and White, one individual who was Black, Asian, and White, and one individual who was Asian, Native American, and White. The majority of the participants, nine, identified as middle class, one identified as lowermiddle class, one identified as lower-middle/middle class, and one identified as uppermiddle class. The highest level education completed amongst participants included two who completed high school, four completed Bachelor's degrees, five completed Master's degrees, and one completed a Doctorate degree.

\section{Procedures}

Participants completed a basic demographics questionnaire and met with a researcher who conducted individual, semi-structured, audio-recorded interviews with them, which were 45 minutes to an hour in duration. The interview involved questions regarding how the participants racially identify themselves, how they understand race, the messages they have received about their race from others, how those messages may have influenced their understanding of race and their own racial identity, and what other factors may have influenced the way they identify themselves. The Demographic Questionnaire and interview protocol are reproduced in Appendices A and B, respectively. After each interview was completed, the researcher recorded notes 
concerning impressions of the interview, the interviewee, and any other reactions or process notes regarding the interview. The interviews were then transcribed and coded to highlight common themes that emerged across interviews.

\section{Data Analytic Procedures}

Data collection and analysis was conducted simultaneously in order to best gather and organize the data throughout the process of the study (Merriam, 2009). This is referred to as the constant comparative method of data analysis, which is essential to grounded theory, in order to identify categories, properties of those categories, a core category that is a central defining aspect of a given phenomenon, and hypotheses that suggest the links between categories and properties. As such, following each interview, the recording was transcribed and the researcher reviewed the transcript along with field notes and observations that had been written during and after the interview. During the review process, the researcher recorded notes commenting on the data, reflections, tentative themes, and developing ideas and hypotheses that may be derived from the first data set and pursued in subsequent data collection.

As data was collected and reviewed, the researcher coded emerging themes initially from a broad, or open, perspective to an increasingly narrow scope through the use of open-, axial-, and selective- coding methods. Open-coding involved making note of all potentially meaningful data, axial-coding then combined concepts that are seemingly related into categories, and selective-coding involved identifying emergent themes within those categories (Merriam, 2009). These processes, particularly selectivecoding, are intended to answer the research question by being used in order to identify a core category that "is the main conceptual element through which all other categories and 
properties are connected" (Merriam, 2009, p. 31); this formed the basis of the theory that is grounded in the data.

\section{Open Coding}

The process open-coding entailed going through each interview transcript line by line and making notations next to every segment of data that appeared to be meaningful in addressing the research question. This process was expansive (i.e. open) to capturing all possibly useful information contained in the transcripts (Merriam, 2009). As such, all data that was in some way related to race messages, internalization of messages, and racial identity development was noted. These codes included broad descriptions of information in the transcripts, such as 'race discussion with family', which formed the bases of tentative categories to organize units of data.

\section{Axial Coding}

After open-coding, the researcher reviewed the transcripts again to begin to group together notations that appeared to be related, which is referred to as axial or analytic coding (Merriam, 2009). This process involved moving beyond noting descriptive codes and into codes that are generated from interpretations and reflections upon meaning. For example, grouping together all notations related to messages received from family, interpreting to identify the types of messages that are received from family, and then code those within the transcripts (i.e., valuation of mixed heritage, conflicting beliefs of family members, differing identity concepts among siblings). Furthermore, in applying the constant comparative method of grounded theory, the researcher compared transcripts with each other as she proceeded forward, as well as returned to previously coded data, to check whether groupings that were identified in the first transcript are present in the 
second, and whether groupings made in the fourth transcript are also present in the first, so on and so forth. This was done to begin identifying patterns that emerged across the data.

\section{Selective Coding}

Selective coding involved identifying patterns and regularities across the data that became "the categories or themes into which subsequent items are sorted" (Merriam, 2009, p. 181). This process was more deductive than the previous coding stages in that in this stage, the researcher examined how well previously identified categories hold up across the data, eliminated categories, and kept others by looking for evidence that support the final set of categories. As noted previously, it is through analyzing these that core categories could then emerge to tie together all other categories and properties (Merriam, 2009).

\section{Researcher Background, Experiences and Biases}

The researcher is doctoral student in Counseling Psychology who identifies herself as biracial, Filipina/White. This researcher has an interest in racial identity research and has had extensive training in diversity issues, particularly those related to race. From her own personal experience of being mixed, this researcher has received numerous messages regarding race and being mixed race from various sources throughout her development. For example, on a regular basis, people ask this researcher 'What are you?', thereby communicating that her ambiguous features are a source of curiosity for people who would like to place her into a racial category. Experiences such as these and their messages have served to inform this researcher's racial identity 
development process and influence the way she identifies herself both publically and personally.

Throughout the course of the study, this researcher made efforts to limit the influence of personal bias on the results. When meeting with participants, this researcher disclosed her biracial identity, student status, and education in diversity issues. If participants inquired about researcher's personal experiences as being mixed, she refrained from such disclosures until after the interview had concluded, in order to prevent content discussed during interviews from being influenced by disclosures. While conducting interviews, the researcher used minimal encouragers that suggested active listening rather than those that might lead conversation (i.e.- ' $\mathrm{mm}$ hmm' versus 'right'). Additionally, this researcher avoided presenting interpretations of participants' disclosures, and follow up questions posed were intended to gather additional information by asking participants to elaborate or clarify meaning in content being discussed, rather than directing participants to talk about a specific topic (i.e.- 'Can you tell me more about that?' versus 'How you think your experiences have been influenced by your racial physical features?'). As noted previously, after each interview, this researcher made notes of impressions of the interview; this served as a way to check for bias when notes were compared to interview transcriptions during the coding process, such as notations regarding topics that were of interest to this researcher versus identification of emergent themes across interview transcripts. Lastly, this researcher attempted to use participants' language, instead of her own terms, in coding emergent themes (i.e., "disownment" and "belonging" versus "family rejection" and "social inclusion/exclusion"). The exceptions to this were terms that best captured themes of content discussed across participants, but 
lacked commonality in participant language (i.e., "cultural consciousness" was used to describe discussions of racial awareness, recognition of social hierarchies, and understandings of values placed on racial categorization). 


\section{CHAPTER FOUR}

\section{RESULTS}

Participants reported the race messages they have received throughout their lives, through how their race was discussed or understood by others in their life- family and friends/peers-, as well as within specific contexts- communities in which they have lived and societal frameworks. Participants also reported how the messages they have received across socialization contexts have influenced how they understand their mixed race identity, and if and how those have influenced the way they racially identify themselves. The following sections will discuss the common themes that emerged from the interviews conducted, with representative quotes from participants to illustrate their experiences, the messages they received, and influences these have had on their understandings of their race and racial identity. Table 1 shows the pseudonyms and basic demographic information of the participants included in the study, to be used as a reference for participant quotations. 
Table 1. Demographic Information of Participants

\begin{tabular}{cccc}
\hline$\underline{\text { Participant }}$ & $\underline{\text { Gender }}$ & $\underline{\text { Race }}$ & $\underline{\text { Age }}$ \\
\hline P1 & M & White, Black, Asian & 31 \\
P2 & F & White, Black & 36 \\
P3 & F & White, Black & 18 \\
P4 & M & White, Asian & 28 \\
P5 & F & White, Black & 30 \\
P6 & M & White, Asian & 35 \\
P7 & M & White, Black & 33 \\
P8 & F & White, Asian & 32 \\
P9 & M & White, Black & 44 \\
P10 & F & White, Black & 33 \\
P11 & M & White, Asian, Native & 33 \\
P12 & & American & 20 \\
\hline
\end{tabular}

\section{Racial Socialization Contexts}

Similarties were found across participants' descriptions of experiences within the contexts of family, friends, and community, and messages received from society as a whole. In the present study, with the exception of societal contexts, no commonality was found among messages about race or racial identity communicated to participants within individual contexts of family, friends, and community. Instead, shared experiences were identified within these contexts through themes that emerged across participants' 
discussions of each context. These themes, and the number of participants who discussed them are displayed in Table 2, and are discussed below.

Table 2. Racial Socialization Contexts: Emergent Themes and Frequencies

\begin{tabular}{ccc} 
Context & Theme & Frequency \\
\hline Family & Disownment/Disapproval & 7 \\
& Sibling Differences & 6 \\
Race Dialogues- Direct & 5 \\
Race Dialogues- Indirect & 7 \\
& Seeking Diversity & 8 \\
Friends & Racial Awareness & 7 \\
& Racial Dynamics & 12 \\
Community & Seeking Diversity & 8 \\
& What Are You? & 12 \\
Society & Racial Categorization & 10 \\
& Normative & 7 \\
& Attractiveness & 7 \\
& President Obama Effect & 6
\end{tabular}

\section{Family}

Disownment/disapproval. Among the participants, there was minimal consistency in terms of specific racial socialization messages that were received from their family members. What was consistent were dynamics that existed within participants' families. For example, five participants reported that one or both of their parents were disowned from their families for being in an interracial relationship. Two more participants reported that while their parents were not disowned, it was clear that participants' grandparents disapproved of the interracial relationship. Participants were impacted by disownments and disapproval from extended family in a variety of ways; five participants experienced reconciliations with their families and received acceptance from grandparents, three noted having formed close bonds with their immediate family to 
cope with the emotional effects of the disconnection from extended family, and two discussed the disownment and disapproval as part of their family history that they did not feel strongly affected by.

As mentioned, five participants reported that their parents eventually reconciled with their families after the disownment or grandparents' expression of disapproval of the interracial relationship. They noted that the reconciliations occurred when the grandchildren (participants and their siblings) were born, and their grandparents have been generally accepting since. P4 (White, Asian) reported that his Japanese mother had been disowned from her family for marrying a White man, but that his grandparents became more accepting when he and his cousins, who are also mixed, were born. He stated,

They didn't love the idea that my dad was White, but [...] they've realized that all the grandchildren are now mixed race. So, there's five of us, and we're all hapas [mixed race Asians]. And for them it's never really been an issue, being mixed.

Participants reported that family reconciliations and acceptance of mixed race children appeared to be a result of their grandparents experiencing feelings of the loss in rejecting family due to their racial prejudices. Additionally, they noted a sense that they as children were viewed as innocent, and undeserving of rejection for their race, which they had no control over. For instance, P9 (White, Black) described how his White grandparents forced his mother to leave their home when she began dating his Black father, but became more accepting when he was born. He commented, "They can't blame an innocent child, so I was accepted by that side of the family for the most part”. 
Among the participants whose parents reconciled with their extended family, there was acknowledgement of the emotional impact felt by their parents. P3 (White, Black) discussed how despite she and her sister always being accepted and treated well by her grandparents, her mother's experience of disownment left a lasting impression on her family, "You still got to see the scars [...] They ended up loving my dad. So it was like "really?" [...] the scars it left my mom, just because she was with my dad and he's a different skin color". Participants expressed a sense of frustration over the difficulties their families experienced due to lack of acceptance of their parents' interracial relationships. They communicated that holding negative views about different racial groups was not sufficient to warrant the degree of hurt caused by the ruptures experienced with family.

In response to the disownments or disapproval of their interracial family, three participants discussed how their immediate family formed closer bonds to support one another. They described their immediate family as a primary support system, particularly around racial issues. Within these families, concepts related to race and views on racial mixing were discussed to varying degrees. P2 (White, Black) reflected upon how her parents and siblings came to rely on each other to build a sense of community with their family. She stated, "they've [her parents] lost both sides of their family because of their decision to be together. So we became very insulated as a result of that, and we were kind of our own little bubble or community." In having this community with family, participants had supportive spaces to discuss concepts of race, challenging experiences with being mixed, and received guidance and support from their parents and siblings. 
Two participants denied experiencing a significant impact from ruptures with their extended family. They acknowledged the disownment as part of their family history that is known to them, but was taken at face value. For example, P10 (White, Black) discussed recognizing her grandparents' disapproval of her interracial family, and noticing that they treated her differently from her fully White cousins. Despite this recognition, she described this occurrence as part of her family dynamic that she is not emotionally affected by.

It was just an odd feeling. I just never really felt at home with them, and I don't think I ever will. You know, they're nice people and they've done a lot for us, but it just has always seemed a little bit strained to me.

She and the other participant were not pleased by the presence of racial prejudice, but had come to view this as part of the norm within their family. In experiencing resignation about this occurrence, they may prevent themselves from feeling emotional pain of familial rejection.

Sibling difference. It was found that among the six participants who had siblings, all reported that they differed from their siblings in how they understood their racial identity. They were more apt than their siblings to identify as mixed- as opposed to one race- and seek racial diversity in their friend groups. Participants attributed some of these differences to differences in racial physical features, such as skin color and hair texture. These physical distinctions influenced the types of racialized experiences that participants and their siblings had, such as encounters with racism, and abilities to pass- being perceived as one race. P7 (White, Black) described how his fair skin and light eye color allowed him pass as White and receive acceptance within White social groups, whereas his sister had more frequent experiences of racism and not fitting in while living in a 
predominantly White community. He noted how others would notice their similarities, but viewed his sister differently.

I've had people ask me, like, 'So, why is that Black girl your sister?' before, because we also look and sound the same. Her voice isn't quite as deep as mine, but we really resemble each other. But she looks Blacker than I do.

P7 and other participants shared that their siblings were more likely to be discriminated against or receive comments involving racial stereotypes if their physical features appeared less racially ambiguous to others.

Race dialogue. Another trend amongst participants was the degree to which racial concepts and issues were discussed within their families. Five participants reported that race was discussed directly within their families, whereas the other seven participants reported that race was generally not discussed. Within the families that race was not generally discussed, three noted that race would occasionally come up in the contexts of racial jokes or references to racial stereotypes. Participants whose families did directly discuss race, appeared to have greater racial awareness, such as stronger understandings of racial issues within society, historical contexts of racial issues, and recognition of oppression based on race and social class. For example, P12 (White, Black) described how her White mother would discuss how to respond to demographic forms or "what are you?' questions. She recalled recognizing at a young age and discussing, that despite how she may personally identify herself, others may view her by the color of her skin.

My mom would always tell me and my brother that if we have to check something on a test or whatever, she said "put Black and White". And she would be like "What are you? You're Black and White, so that's what you put." And [...] I remember we told her- I thought it was kind of interesting that we were so young and we said this- [...] "we are pretty much like a piece of white paper with black ink on it. People are going to see us as Black". 
Of note, only one of the five participants who identified as part Asian, compared to five of the eight participants who identified as part Black, reported that his family directly discussed issues of race and racial identity; this particular participant is multiracial, as his mother is Black and Asian, and his father is White. It is difficult to determine whether this may be attributed to specific cultural factors in Asian interracial families, or individual factors among the participants. Due to the participant's mother's own experiences of being mixed, she was conscious of challenges that mixed race people face, and discussed these directly with her son. Among the other participants, two suggested that lack of racial dialogue in their family stemmed from being raised primarily by their White parent or White family members. The other two participants felt that their Asian parent attempted to adopt White culture to cope with cultural shame from experiences with oppression and racism. P8 (White, Asian) stated that her father wanted to "erase" his Chinese culture so that he and his children may be treated as being Whitegranted greater access to privilege-, "My dad tried to act like his accent was flawless actually. He joined the tennis team, he did bowling. He was the kind of immigrant that really tried to erase the motherland as much as possible."

Four of the seven participants from families in which race was not discussed, reported making more conscious efforts to build their racial awareness through education and engaging in racial dialogues with other people of color. These efforts were made to better understand racial issues, and consequently their racial identity, to make up for the lack of guidance received from their family. For instance, in response to her father's attempts to minimize her Chinese heritage, P8 reported experiencing confusion about her racial identity while growing up, and has since sought to educate herself on racial issues; 
her parents did not provide guidance or language to help her understand her mixed background and the racist encounters she experienced, so she has found greater understanding through her education and engaging in racial discourse.

\section{Friends}

Seeking diversity. Eight of the participants discussed having preferences for racially diverse friends and have actively sought diverse friend groups as they have gotten older. Six participants noted, that while they were young, there were fewer opportunities for diversity in their friend groups, due to the racial make-up of the their communities, as well as racial segregation within social groups in their schools and communities. Participants attributed seeking diverse friends to their desire to connect with others who may better understand their experiences related to race, and had found benefits of greater acceptance and connection when forming relationships with other people of color. For example, P12 (White, Black) remarked, “I understand you shouldn't pick your friends based on race, but you gain something from having Black friends that you aren't going to gain from White friends." She noted additionally, that while she valued her White friends, having Black friends provided a support system of individuals who were more understanding of experiences of racism, who could better recognize less overt racial discrimination, and who were generally more racially aware and open to engaging in dialogues about racial issues. Similarly, P5 (White, Black) commented, "at times I feel like certain views I have, African Americans tend to understand more of where I am coming from [...] I feel like people can identify and understand”.

Such sentiments were echoed by the seven other participants, who felt that they were more likely to have shared experiences and understandings with other people of 
color than with monoracial White individuals. Furthermore, all participants referenced benefits of developing relationships with other mixed race individuals, as there is greater opportunity for connection regarding experiences that may be unique to mixed race people, such as frequently being asked "What are you?" by others. P4 (White, Asian) noted, "A lot of my friends were mixed [...] I was really lucky to have a group of guys who all kind of knew what the experiences were like for us". Participants expressed feelings comfort and relief when with other mixed people, as they felt less pressure to have to explain themselves and their experiences; conversations could instead involve reflections and support around common experiences and challenges.

Racial awareness. Additionally, seven participants reported a desire for racially aware friends, regardless of their racial background. For example, P1 (White, Black, Asian) noted that all of his White friends identify as being 'anti-racist' and regularly engage in dialogues about race and social justice issues. He stated, "I mostly surround myself with people of color, or people that have an anti-racist politics. The conversations are usually intellectually generative, interesting, sometimes tense, but pretty upfront." P1 (White, Black, Asian) and other participants suggested that in socializing with people who are racially aware, they can more readily feel supported and engage in dialogues about race that felt rewarding. P8 (White, Asian) reflected upon her own growing racial awareness, and recognizing for herself both a sense of burden from her experiences of racial prejudice, and the richness that can come with connecting with others on those issues. She commented 'I'm realizing race is important and understanding my burden, this burden of gold that I'm carrying with me everywhere. It's important that people understand that about me." She noted that in having racially aware friends, regardless of 
their racial background, she has had the opportunity to explore issues that she grapples with, as well as challenge racial assumptions of herself and others in a supportive environment.

\section{Community}

Community racial dynamics. Participants had some difficulty describing racial socialization messages they received in community contexts, as they varied in the types of community environments they grew up in, and messages about race were generally indirect. For example, three participants stated that racial issues were not discussed often within their communities, but neighborhoods were clearly segregated along racial lines; two participants additionally noted that they would hear comments made about "the bad side of town", which referenced to neighborhoods in which racial minorities predominantly lived. These participants suggested that while there were no directly negative views about racial minorities expressed within their communities, there were implicit values in maintaining divisions between White neighborhoods and those of people of color; this communicated underlying prejudice against people of color. P7 (White, Black) reflected, "I remember a fear of driving through the closest city in the "bad side of town". [...] In a community like that, there's a lot of racial profiling and prejudice underneath the surface, but it wasn't really discussed." In keeping racial prejudices unspoken, it may have been easier to ignore racial issues that existed within these communities and maintain a façade of racial tolerance and acceptance.

Five participants grew up in predominantly White communities, two grew up in diverse communities, and five had experiences living in both White and diverse communities. Across participants, there were no common trends related to the racial 
make-up of their communities and the types of messages received nor racialized experiences within these communities. In both White and diverse communities, there was variability in the degree to which participants experienced acceptance from others, questions about their race, and encounters with racism. While all participants expressed feeling generally more accepted while living in diverse communities, five participants noted being questioned about their race more frequently, as well as encountering racismboth from White individuals and people of color- more directly in these communities. Three participants discussed experiencing direct encounters with racism while living in White communities, whereas six participants reported feeling accepted. However, three of those six noted sensing prejudices that were not spoken publicly. For example, P11 (White, Asian, Native American) stated, "Everybody talks behind your back. Nobody talks to you in your face. So I didn't really hear much of that, but I know it was going on". It seems that acceptance and racial tensions existed in both White and diverse communities, but tensions were generally unspoken or indirect in White communities as opposed to diverse communities.

Seeking diversity. Eight participants reported actively seeking to live in diverse communities as adults. Similar to the earlier discussed desire for diverse friend groups, participants felt that living in diverse communities provide more opportunity for acceptance and understanding. Despite the five participants who had acknowledged more encounters with racial questions and racism while living in diverse communities, they felt that having racial issues acknowledged, created more space to engage in productive dialogues about race. Additionally, there are greater possibilities of building connections with other of people who are racially aware, across racial backgrounds. Four participants 
spoke about having developed greater awareness of themselves and others through their experiences in diverse contexts. Lastly, five participants noted desires to live in diverse communities as a way of finding belonging and not standing out as different. P8 (White, Asian) reflected that she "really need[s] to see on the street, different faces, different backgrounds in order to feel like there's a home”. Similarly, P7 (White, Black) commented,

When I'm looking for an apartment with my girlfriend, I'm like, "We've got to find somewhere where I can be a six-foot-tall mulatto with a red fro and walk around [laughs] — and not feel like I stand out too much and not get stared at on the sidewalk".

What are you. Connected to experiences of standing out as different, all 12 participants discussed experiences of having their race questioned by others, in the form of the question 'What are you?' While all participants noted this question coming up occasionally with friends, it was more frequently asked by individuals encountered within community contexts. Participants described a variety of scenarios in which they were approached by strangers and asked questions such as 'What are you?', 'What's you're nationality?', and 'Where are you from?', 'Where are your parents from?' or 'Where are you really from?'. Although those questions can be interpreted in a variety ways- i.e., inquiries about job title, or region of the United States that one was born-, participants recognized that individuals posing these questions, were asking them to racially identify themselves.

All felt that the questions often come from a place of curiosity about their ambiguous racial features, as well as others' desire to place them into categories from which they may then make assumptions. For example, P12 (White, Black) commented, 
"People think race is a huge deal and if they can categorize you, then they can think all these things about you, without getting to know you. And if they can't categorize you, they have to ask, because they just don't know what to think." Five participants noted feeling a sense of being devalued or dehumanized by being categorized in this way, as there is often minimal attempt from strangers to get to know them after they have racially identified themselves. Participants suggested that after learning their racial identification, strangers may make assumptions based on stereotypes or preconceived notions about the racial groups they belong to; as such, there may be limited motivation to learn more about participants' as individuals separate from their racial background.

Participants expressed a mixture of resignation, frustration, and some appreciation for people's curiosity about their racial background. Resignation was influenced by how frequently participants receive questions about their race, that they have consequently developed standard, emotionally detached responses; P2 (White, Black) commented, “I always get the question. Probably every other day from somebody". Five participants expressed frustration with these questions, due to not liking importance placed on racial categorization, and feeling that people are asking 'the wrong questions' by not directly asking about race. In line with the afore mentioned sense of devaluation, P8 (White, Asian) shared her frustration in saying, "people feel they have a right to know, and that trumps your right to privacy, your right to selfhood, personhood". She and the other four participants reported experiences of people asking 'What are you?', then becoming upset or offended if participants declined answering, or gave vague responses. Messages implied in this may be that others are uncomfortable with being unable to categorize mixed race people based on their physical features alone, and that feel they have the right 
to this personal information. Four participants expressed appreciation for 'What are you?' questions, as they felt that questioners might be attempting to not make assumptions about them. These individuals viewed 'What are you?' questions as an opportunity to share about themselves, and potentially correct, or even prevent, assumptions being made. For example, P10 (White, Black) stated 'I’ve always just thought, if someone wants to know what you are- rather than them just guessing or putting you into a box- they might as well know exactly what it [your race] is."

Seven participants reported that they tend to provide playful responses to 'What are you?' questions, as a way to challenge people to directly ask about their race. A couple of participants commented that 'What are you?' in and of itself is an odd and vague question, as one can provide literal responses (i.e.- 'I'm male', 'I'm human'), mood states (i.e.- 'I'm happy'), etc. For example, P1 (White, Black, Asian ) shared how he sometimes provides vague or evasive responses to vague questions about his identity 'I might respond 'tired,' 'sleepy', and I'll sort of push them until they say like "What's your background?” And I'll say, “Oh, I was raised in Colorado.” He noted that people get frustrated with him when he does this, but he sees this as an opportunity to potentially challenge or educate people about racial assumptions and how those questions can be experienced. P10 (White, Black) expressed that she enjoys providing playful responses to 'What are you?' questions as a way of highlighting the vagueness of those questions, and to communicate that others need not tiptoe around questions of race. She described an example of her responses, “'Well, I'm American. I'm from Chicago.' And then you're kind of playing along, because you're like, 'What do you really want to know?' 'Get to the question!'” Participants agreed that they preferred that if people are going to ask 
about their racial background, that they ask more directly, rather than having participants infer what others mean in asking.

\section{Society}

Racial categorization. Ten participants highlighted that 'What are you?' questions communicate a larger societal message that race is important. They discussed how being able to categorize people and ascribe meaning to those categories, permits the creation of social hierarchies that can place certain groups of people over others. Six participants felt that the concept of race, in and of itself, is meaningless or neutral, but that society has placed value on racial categories. P8 (White, Asian) stated that race is, ...important only to the extent that we make it important, and that we have made it important. I think race is actually very neutral. It is what it is. [...] But we've added this value language to it $[\ldots]$ in order to meet reality where reality is.

Participants commented that instead of race being understood as simply a part of one's identity and ancestral history, dominant society often perceives people of color according to preconceived notions of their racial category alone; as such, it becomes acceptable that racial minorities are more predominantly represented in underprivileged positions in society, because it assumes deficiencies within those groups, rather than lower positions being a consequence of social systems of oppression. Building off of this concept, four participants made references to historical contexts of race relations in America, such as 'the one drop rule', slavery, and subordination or Asian, Latino, and Native American people, that underlie present attitudes about different racial groups and systems that maintain social hierarchies. C7 commented, "generally, White has the most advantages. $[\ldots]$ White is at the top-Black is at the bottom, with others coming in between. [...] That's my perception of how it works." 
Normative. Despite these social inequities, all participants felt that society is generally progressing toward greater acceptance of racial diversity and mixed race people, particularly amongst younger generations. Seven participants referenced that with greater acceptance of racial diversity, interracial relationships have become more common, and has influenced growing numbers of mixed race people being born. As such, being mixed race has become more normative than an anomaly, as was the case in previous generations- including those of the participants themselves. For example, P5 (White, Black) reflected,

As a whole society, I feel like years ago, [...] people thought biracial or mixed children were probably more confused than anything, or not as accepted because maybe they didn't see it as much. Whereas now, [...] at this point in the game, you're mixed with something. If it's not $50 / 50 \ldots$ You definitely have more multiracial and biracial [people]. It's definitely going towards that, especially younger generations, people are more accepting of these types of backgrounds.

The consensus among participants was that as mixed race backgrounds become more common, younger generations and society as a whole will continue to become more accepting.

Attractive. Seven participants noted that it has become increasingly common to see mixed race people represented in the media, whether it be through models in magazine and television advertisements, or the presence of mixed race celebrities and public figures, such as Tiger Woods, Halle Berry, Soledad O’Brien, and President Barack Obama. Granted, participants also expressed that increased representation and positive attitudes about mixed race people tended to be associated with superficial messages that mixed race people are more "attractive", "beautiful", and "exotic" than monoracial individuals; particularly monoracial people of color. Three participants viewed this 
message as a positive example of increased acceptance. P11 (White, Asian, Native American) commented, 'I think it's turning into something that's actually respected now. Or looked at as a beauty now [...], in certain forward thinking places". Two others felt a mix of flattery and objectification, as P7 (White, Black) noted, "sometimes being mixed, you get kind of the exotic angle. [...] people think it's interesting. People think it's new, and $[\ldots]$ that makes them interested in you. [...] That can be flattering, but it can also feel objectifying". Two participants felt discomfort and resentment related to feeling objectified. P2 (White, Black) additionally expressed anger that people of color may be viewed as being more attractive when they have Europeanized features when racially mixed with part White heritage. She stated,

It just makes me so mad that beauty is perceived as being Europeanized [...] I think you see more and more coverage on TV and magazines- all forms of media, but still all you see is pretty much a Europeanized version. All those you see on TV, do well if they ascribe to those [...] Europeanized things.

President Obama effect. Six participants discussed differing portrayals of President Obama as the first- mixed race- Black president. Two participants felt that President Obama's election represented a societal shift towards greater acceptance of diversity. They also thought his presence in the public eye generated increased positive interest and curiosity about mixed race people. Granted, they and four other participants discussed the current climate of divisiveness in politics, which they attributed to both overt and underlying issues of racism, and people feeling uncomfortable with having a Black man in a position of power. P10 (White, Black) commented, "I feel like this animosity or something. [...] it stopped being about 'What are some of the issues with the President?', and 'What haven't we gotten done?', and more of, like, an attack on color.' 
Another participant also questioned whether President Obama would have been elected, or have even been recognized early on in his political career, if he were fully Black, instead of mixed. It was suggested that being part White, may have buffered some of the racist attitudes toward President Obama, thereby creating opportunity to rise to his current position of prominence.

\section{Racial Messages}

Among the participants, there was minimal consistency in terms of specific racial socialization messages that were received from specific sources- family, friends, community-, but there were common themes of messages received across these socialization contexts. As shown in Table 3, themes included belonging, impacts of racial physical features, racial teasing, and racism.

Table 3. Race Messages: Emergent Themes and Frequencies

\begin{tabular}{cc} 
Theme & Frequency \\
\hline Belonging & 9 \\
Racial Physical Features & 11 \\
Racial Teasing & 8 \\
Racism & 7
\end{tabular}

\section{Belonging}

Nine participants described themes related to belonging. These included statements regarding experiences of being included and excluded in different contexts, varying experiences of fitting in within their family or social groups, and experiences of being an "outsider". Five participants described how being mixed provided opportunities for greater inclusion in different social contexts; in having more than one racial heritage, they may share commonalities with a wider range of individuals, and may be able to 
relate to different cultural experiences. For example, P7 expressed, "I feel like it allows me to cast a wider net. There's more of a chance of me having something in common with somebody". Some participants noted having shared experiences with members of both dominant and racial minority groups, which permitted the ability to connect with others on those shared experiences. For example, participants could speak to others regarding aspects of privilege granted to them, as well as experiences of prejudice and discrimination. Additionally, three participants referenced feeling as sense of connection with gender and sexual minorities, as there are shared experiences of being part of a group, but not fully (i.e.- a gay man may have privilege in society due to his gender, but experiences discrimination due to his sexual orientation). P8 (White, Asian) commented on relating to her GLBT friends in "the sense of otherness, of not quite fitting. I feel very comfortable around the GLBT community, because they look like they fit in, but they don't. [...] which is kind of how I feel sometimes."

As has been suggested in previous research, participants identified that while they may be accepted in more contexts than might be permitted for monoracial people, there are challenges in not being fully part of one racial group, and as such, they do not entirely fit in with any particular group. In line with this, P2 (White, Black) noted, "it can be a little bit tough to navigate the world, because you're never really on one side or the other. $[\ldots]$ or maybe if you have 3 or 4 different races [...]. You're always a little bit of this and a little bit of that." She communicated that being part of a group provides opportunity for connection with that group, but not being a full member of any one group can create a sense of distance when attempting to connect. Four participants expressed feelings of sadness and hurt that can come with not being fully part of any distinct racial group. The 
concept of not being "enough" of a given racial group was influenced by both direct

and indirect messages regarding the degree to which they may relate to the experiences of distinct racial groups. Participants noted that they were often cast in an outsider status due to not being “enough”. This was highlighted well in P7's (White, Black) comments,

The times I felt like it [being mixed] was bad, was when people [...] of one race or the other would treat me like I was then not of that race enough. Some people would say, 'See, you are this,' [...], and then some people would be, 'Then you're not really this.' [...] That hurts, because I'd like to fit in somewhere. I'd like to be accepted. Being alienated doesn't feel good for anyone.

P8 (White, Asian) expressed a similar sense of alienation that come from being asked 'What are you?' questions, as these directly communicate that she is seen as different. She and other participants discussed how such questions would not be asked of them if they were monoracial, and did not have racially ambiguous features. As such, notions of belonging are implied in 'What are you?' questions. P8 stated,

In a society that says I don't belong here. When you get the 'what are you?' questions. [...] You would never think of going up to a White woman and saying "What are you?" Why not? Because she belongs. You know where she belongs. [...] Whereas there is no space for us.

Seven participants reported coping with messages of not belonging, by becoming accepting of having a unique identity, and enjoying being different from others. For example P10 (White, Black) stated, “it's harder to fit in and have to be somebody that you're not, whereas I just chose not to fit in and just [...] be different, and live with that" Three commented on feeling more "interesting" in being racially different, and finding a sense of belonging within themselves in embracing their mixed heritage. 


\section{Racial Physical Features}

Eleven participants discussed messages regarding physical features of race. Seven spoke about being considered more attractive due to being racially mixed; participants have received comments about having "good hair", attractive skin tone, and "interesting" features that family, friends, and individuals in their communities remarked on as being appealing. Seven participants additionally commented on the wide use of mixed race individuals as models in advertisements on television and in magazines, which suggests that racial mixture is seen as beautiful. These messages brought up conflicting feelings amongst participants, as some expressed appreciating positive attention, and viewed compliments as a sign of society becoming more accepting of diversity, whereas, others expressed sensitivity to the message that being one race, particular a minority race, is unappealing. For example, P12 (White, Black) stated,

I have had family friends that are older, or my grandma who will say, "oh you have good hair". And I don't like that at all, because I believe any hair is good hair. My hair is curly but I don't think if I was fully Black, [...] my hair would be any worse. So I don't like being told that I have good hair or stuff like that, because by saying that, I know that you're putting down someone who is fully Black who has maybe kinkier hair or darker skin.

Three participants commented on how their racially ambiguous features influenced situations of being perceived as a different race than one actually is, "passing" as one race, and has prompted participants to engage in racial discussions to clarify misperceptions about their race, or even presumed positions on racial issues due to perceived race of participants. P8 (White, Asian) commented, "since my face is more ambiguous. You know like, 'what are you?' I could pass as White. So I’ve been in the conversation $[\ldots]$ where I'm in a White crowd and their talking about 'those minorities'." 
She and other participants noted that passing or being misperceived as other races, has provided them with opportunities to challenge racial assumptions, particularly in social contexts in which they can then engage in productive racial discourse with friends and peers. Although, these experiences, at times, also influenced difficult feelings of anger or frustration when being misperceived by others. P3 (White, Black) expressed frustration when people comment on her features, but do not recognize her as being mixed, as she found it to be discrediting of her heritage. "I've had people say 'oh are you a light skinned Black girl?' I'm like 'I'm not a light skinned Black girl, I'm biracial.' I would not be this color unless I was partly White."

Related to the theme of belonging, four participants discussed how their physical features influenced how much they resemble their family, as well as the degree to which others may perceive them as being part of their family. For instance, one participant recalled being out with her White father, and someone made a comment about them, assuming that she was his girlfriend; despite her physical resemblance to her father, their familial relationship was not recognized due the participant being seen only as Black. Others commented about how they may stand out when with their immediate and extended families. P4 (White, Asian) shared,

I don't really fit in on either side because on my White side, they're all short White people who are very light skinned. So then there's me, tall, and I'm half Japanese. I look like my dad- but when we're standing right next to each other. And then my Japanese family, I stand out because I'm tall, and I'm lighter than everybody else.

Such experiences were described with undertones of sadness in being in some ways set apart from their family, due to their appearance. On the other hand, participants coped with this through the use of humor, poking fun at their physical differences. For instance, 
one participant noted her tendency to joke that her darker skin tone comes from being better able to get tan than her White mother.

\section{Racial Jokes and Teasing}

Eight participants discussed experiences with racial jokes and teasing, primarily from family and friends or peers. These experiences were described as often being wellintended jests that could at times elicit feelings of discomfort and pain. For example, P6 (White, Asian) described his perception of being teased by friends, "I took the teasing to be good natured at the time, but I think there's probably a level of $[\ldots]$ that maybe was a little less than good natured at times and made me uncomfortable." Participants noted that feelings of discomfort were influenced by and underlying message that they were perceived as different, and was connected to the earlier described theme of belonging. Additionally, teasing would come from both White individuals and people of color; being teased by other people of color appeared to be particularly painful, as this further highlighted their minority status within a minority group. For example, P7 (White, Black) reported,

I had a boss who would tease me for being light skinned. [...] it was good natured, but $[. .$.$] it kind of stung because he was Black. He would sometimes pick$ on me, make jokes about me being light skinned or laugh at the way I talk.

Participants also discussed how racial teasing often involved racial stereotypes and assumptions. For instance, participants who were part Asian noted jokes involving their ability to use chopsticks or skills in math. P4 (White, Asian) commented, "I know maybe people are joking, but I get a lot of questions about the part of me that's Asian. So, it's like, 'Oh, will you fix my computer?'”. Participants who were part Black would hear jokes referencing being "ghetto", or being from bad neighborhoods. For example, P3 
(White, Black) stated, "I know it's joking but really think about what that is implying. That because if I'm Black, I have to be aggressive, or mean, or 'ghetto'.' Participants commented that they felt the intention of these jokes were not to be mean or hurtful, but that emotional affect was influenced by microaggressions in being stereotyped with teasing comments.

\section{Racism}

While the participants viewed racial teasing as hurtful, but generally coming from a good-natured place, experiences with racism had a deeper emotional impact. Seven participants discussed experiences with racism that either occurred directly or they witnessed occurring with family or friends. Four participants discussed being taunted with racial slurs while at school, which included specific slurs related to being mixed. P2 (White, Black) referenced slurs she was targeted with by Black girls in her school, "You know all your typical biracial slurs- half breed, zebra, oreo.” These slurs, again, contributed to the concept of feeling like an outsider, particularly as they would get targeted with negative racial assumptions from all sides. For instance, receiving racist comments and treatment from White people for being a person of color, and receiving negative comments and treatment from people of color for potentially benefitting from White privilege. Three participants who were part Black, discussed being harassed by Black peers due to assumptions that the participants saw themselves as being better for having lighter skin.

Four participants discussed recognizing racism and being treated differently by others as they got older, particularly amongst part Black participants. For instance, one participant discussed the pain of recognizing that others began to view him as being 
threatening as he became a teenager, and was no longer allowed to spend time with some of his White friends. Two participants discussed experiences of being assumed to be criminals, and have been followed closely while shopping in stores. Such experiences influenced awareness of their minority status in ways they may have previously ignored. P3 (White, Black) commented, "that [racism] clearly puts it right in front of my face, 'you're Black”,

Two Asian and White participants denied ever experiencing overt racial discrimination, and were more commonly subjected to racial teasing. They attributed this to their perception that while prejudice does exist, society generally holds less negative attitudes towards Asian people. P6 (White, Asian) reflected,

I rarely feel discriminated against. [...] most of the racial discrimination issues seem to be more centered towards or against Blacks, in my opinion. Whereas Asians, there's still a lot of bigotry everywhere you go, [but] it seems like there's less persecution against Asians than maybe Blacks or Latinos.

He noted further that stereotypes of Asian people being smart and successful may influence his experience of less overt forms racism, and instead being lightheartedly teased according Asian stereotypes. It may be that the stereotype of Asian people being a 'model minority', serves a buffer to more frequent overt discrimination; this may be further heighten in mixed Asian and White individual, as they may in part benefit from aspects of White privilege that may protect against some discrimination.

Experiences of racism were associated with deep feelings of pain and anger. Four participants became emotional while recounting these experiences. P1 (White, Black, Asian) stated, 
You are always worried that on some level there is a fundamental flaw with you in the way that dominant culture perceives you. And you can't help but internalize that. And you can't help but start to feel bad about it, or resentful, or angry.

Participants shared how these experiences have influenced them to advocate for themselves and others, as a way to make their emotional reactions productive. This included challenging others when they make racial assumptions or engage in explicitly racist behavior, as well as engaging in dialogues about race in order to encourage greater awareness among others about racism.

\section{Impact of Race Messages}

\section{Message Influence on Understanding of Race}

When asked how the messages participants received have influenced their understanding of being mixed race, common themes arose, which are presented in Table 4. These included cultural consciousness, interests in engaging in racial discourse, pride in one's mixed race identity, and awareness of mixed race privilege.

Table 4. Message Influence of Understanding of Race: Emergent Themes and Frequencies

\begin{tabular}{cc} 
Theme & Frequency \\
\hline Cultural Consciousness & 7 \\
Racial Discourse & 7 \\
Pride in Mixed Race Identity & 7 \\
Mixed Race Privilege & 5
\end{tabular}

Cultural consciousness. Seven participants discussed having developed, and continued to work on building cultural consciousness in responses to the messages they have received throughout their lives about race, and being mixed. These individuals discussed learning the importance that is placed on race within our society, which has 
consequently impacted their experiences in other racial socialization contexts of their family, social relationships, and community environments. P1 (White, Black, Asian) commented, "I think it [racial socialization messages] made me more conscious of forms of injustice" within society, based on meaning ascribed to race as a social category. As discussed previously, the value placed on race has been communicated through pressures to categorize themselves and others according to race, as is implied by frequent "What are you?" questions. Additionally, hearing stories about their parents' being disowned or disapproved of for being in interracial relationships informed participants that racial mixing was viewed negatively, and implied values placed on maintaining divisions between races. Values for such divisions were further highlighted in participants' recognition of racial segregation within social groupings and the communities they have lived in, as well as understandings of social hierarchies that perpetuate divisions. For example, P2 (White, Black) reflected, "I think the messages have definitely told me that race is very much tied to social standing." There was also awareness among participants that experiences of racial teasing and more explicit racism, were influenced by negative stereotypes and attitudes toward different racial groups.

Participants shared that racial messages helped them to recognize not only views on individual racial groups, but also helped develop awareness of their mixed race identities. Namely, it was acknowledged that more often than not, they would be perceived, and treated in line with, their minority racial status and the stereotypes and attitudes associated with that status. For instance, P12 (White, Black) expressed increased recognition of her Black identity based on her experiences. She stated, "I recognize being Black more because that's the part of me that the race is going to come 
up on a daily basis with different experiences. The White part of me isn't going

to." Similarly, P3 (White, Black) reflected that implicit messages she had received about race were easy to ignore until she had a direct experience of racism that increased her overall racial awareness. She commented,

The little implicit things happen, but a lot of time [...] you don't really think about them, and it's just so easily ignored. But when you see something like that [...] like 'oh, there's something going on here because of her race', then that makes you kind of think about [...] what does it mean to be biracial.

Racial discourse. Falling in line with developing cultural consciousness, seven participants discussed enjoying engaging in racial discourse. Such conversations provided these participants with opportunities to further build their own racial awareness, through discourses that explore racial issues within different contexts, and having space to examine questions they are sorting through in relation to their own racial identity. P8 (White, Asian) reflected upon the importance racial discourse has had for her in grappling with her racial identity,

I have this eternal hunger to talk about race. [...] to have a space available for discussion. [...] Self-expression is really important for me. [...] I can put words to all of these things that don't have words. [...] for the question of like, 'what do you do with all of this?' What do you do with this mish mash of life experiences?

She and other participants, particularly those who had limited opportunities for racial discussions within their families, noted a sense of catharsis or freedom in being able to explore racial topics openly with others.

Racial discourse also provided participants with space to educate others and challenge racial assumptions, particularly in terms of racial stereotypes and prejudices. In doing so, participants discussed being able to increase understanding between themselves and others. Three participants noted that they will provide education to others about 
historical contexts of racial issues and invite further conversation about present systems of oppression, as a way to inform or correct misunderstandings. Five participants also reported directly confronting racial assumptions they hear being made about themselves or others. For instance, P10 (White, Black) commented upon her tendency "call out" or challenge people who make assumptions about her based on their perceptions of her racially ambiguous features, and the expectation to choose to identify with one race. She stated,

[I] call it out.[...] You might see me as different, but it's not like I act one way or the other. [...] I identify with both cultures and I can talk to you about either one. And I've lived both of them, and I haven't chosen one or the other.

She and three other participants noted further that when they hear racially prejudiced remarks, in addition to challenging those, they try to inquire about others' perspectives to better understand what is influencing those prejudices.

Additionally, four participants shared how these dialogues helped them to express difficult emotions regarding racial issues, as well as develop sensitivity to others' perspectives. P1 (White, Black, Asian) discussed sharing with others his feelings of anger and sadness about racial and social injustice. He noted recognizing that he has made mistakes due to his own biases, and this has influenced increased sensitivity when approaching difficult conversations about race. He stated, "One of the thing that it has taught me, especially in moments- like when friends have said something that's offended me- is how to be forgiving. Discursively forgiving. And to say, 'Here's why that was a problem." Similarly, P12 (White, Black) reflected upon how her experiences as person of color have influenced increased cognizance of challenges that she and other racial 
minorities face; this has prompted her to consider her own context when responding to offensive comments,

If you're a minority, your race is constantly in front of you. You go into a classroom, and it's all White people and you're the only person of color, you notice it. If someone says a racist remark or someone uses slurs, [...] then you recognize it and you're like 'it offends me too, because I am a minority'.

In owning their own experiences, others may be more receptive to expressions of difficult emotions and challenges to racial assumptions.

Pride in mixed race identity. Seven participants reported having developed a sense of pride in their mixed race identity in response to the messages they have received throughout their lives. Despite difficulties with messages of not belonging, values placed on racial categorization and physical features, or negative views about people of color communicated through experiences of racial teasing and racism, participants felt that these have influenced them to be reflective about their racial identity; to determine for themselves where they feel they fit, and develop a sense of pride in having unique identity. P11 (White, Asian, Native American) shared about his struggles with feeling like an outsider, then coming to feel pride about being mixed,

It's made me question it. I've had to come to terms with a lot of stuff [...] of what $I$ am. [...] I view myself after all of the good and the bad things I have experienced in my life. Now I see that it's just me. I'm not part of any category, which was the hardest thing I had growing up. Now it's something I'm most proud of.

Similarly, P7 (White, Black) reflected upon having developed pride in his mixed identity by asking himself various questions about his identity, in terms of 'what' and who he is, rather than being defined by others. Examples of questions were,

Who am I comfortable around? [...] How can I get to know all sides of myself? How does it feel to be of one ethnic group or another, or both? What parts of my 
ideas, my feelings, my perceptions, my experiences could attributed to being part of one or both, or sort of neither of these groups?

In grappling with these questions, participants concluded that being more than one race provided a sense of 'richness' to their background and experiences. In response to inquiry about how messages have influenced her understanding of her mixed race identity, P5 (White, Black) stated, "I just thought of the word 'rich'. Not in terms of money. I just feel like you get a unique experience from both." She and the other six participants discussed that having a mixed background provides a unique perspective on concepts of identity; in recognizing that their identity is not entirely shaped by one race or another, there is also recognition that their identity is not shaped entirely by race, and that factors such as gender and social class have a strong influences on how they understand themselves. As such, they noted feeling proud that their experiences in being mixed allowed them to develop a strength of being able to view others in an open and holistic manner, instead of making automatic assumptions based on any given social identity factor of another person; there was a sense of empathy towards others being stereotyped or judged for singular aspects of their identity, which influenced participants to be reluctant to treat others as they have been treated. For instance, P10 (White, Black), commented that being mixed has,

helped me understand people better [...] almost anybody's kind of background. When I hear about different people's lives [...] I just am like, "oh, this is so interesting to me". Because, everybody has something different that they've gone through. [...] It's made me a lot more inquisitive and interested in what other people do, and how it's shaped them to be who they are now.

Participants expressed awareness that being interested in the lives of others and understanding identity as a multifaceted construct is not a strength unique to, nor 
universal, among mixed race individuals; although, they all felt that their experiences as mixed race individuals strongly influenced this strength. Had they not been questioned about their identity so frequently throughout their lives, or been in contexts in which they only felt they partly belonged, or been treated in prejudiced ways, they may not have been challenged in quite the same way to reflect upon everything that makes up their sense of identity, both as mixed race people, as well as complex individuals who happen to have mixed race backgrounds. P8 (White, Asian) commented on this perception of strength in being mixed, "It can be gold. There are so many opportunities to build bridges in ways that people who are monocultural cannot."

Mixed race privilege. In connection to cultural consciousness, five participants reported that the messages they have received have influenced awareness that individuals of mixed race descent- particularly those who are part White- may benefit from unearned privileges. They suggested that both the ability to pass as White, or having ambiguous racial features that may be viewed as attractive, or non-threatening, can influence being granted advantages they might not otherwise receive were they fully Black or Asian. Examples of privilege discussed included, being targeted with racism less frequently than monoracial minority peers, being viewed by others as being more attractive or interesting due to racial mixture, and being able to choose how to racially identify in different contexts. Participants expressed feelings of discomfort and guilt about receiving unearned privileges, and discussed ways they have attempted to respond when privileges are granted. For example, P1 (White, Black, Asian) shared about having gone into academia and conducts research on cultural oppression as a way of coping with the shame he feel about his privilege, and to challenge the systems that have created this. 
I think the sort of affective dimension is shame to some extent, and that is linked to the Whiteness. I think there are times that I feel a sort of shame about the lightness of my skin. There's nothing I can do about that. If anything, I see something that can be productive, because I can use that shame to sort of produce work that will try at least in some small way to the undoing of the privilege that is a mark of my Whiteness.

P2 (White, Black) also reported making efforts to challenge systems of oppression. She noted that in recognizing the privilege she has been granted, she has been motivated to work as a nurse with underrepresented populations and advocate for access to quality healthcare. She commented,

[...] lighter skin does get you more advantages [...] You go up on the social ladder essentially. I was aware of that and I felt guilt as a result of that, and I carried that guilt for awhile [...] I think that drove my desire to specifically work with a minority population. I mean, not so much guilt now, but the need is there.

All five participants who spoke about mixed race privilege, additionally commented that challenging privilege was common in racial discourses they engaged in with others.

\section{Message Influence on Racial Identification}

In discussing how participants racially identify themselves when they are asked about their racial background, five participants identified as biracial, three as mixed, three stated that they identify differently based on the context they are in or their mood, and one participant identified as one race but would specify her mixed background when asked follow up questions. This participant noted that when she identifies as Black, people often ask her additional questions about her background due to her lighter skin tone. Similarly, 10 of the participants reported that they always specify their races and/or ethnicities, (i.e., Black and White, Korean and Swiss) when others ask about their race. By specifying their race or ethnicity, individuals suggested that this reduces additional 'what are you?' follow up questions. The implicit message they have received from being 
asked to racial identify themselves with 'what are you?' questions may be that identifying as 'mixed' or 'biracial' are insufficient responses.

On demographic forms, when given the opportunity to check multiple boxes to identify their race, all participants identified their multiple races. When asked to check one racial category only, participants varied in their responses. Four identified with their minority race, rather than White, four identified as 'other', and three stated they would determine their responses based on assumed purpose of identification question, their physical indicators of racial categories, or mood at time of completing forms. Participants expressed frustration at being forced to choose one race to identify themselves on forms, as choosing one is not necessarily reflective of their experience and sense of self. P5 (White, Black) noted,

I give credit to both of my experiences and my background so I don't want to choose one over the other [...] It may be one of those things where I identify more with one than the other, but I feel like both of my parents have clearly made me, so I identify with both them. So that's why I would check both or the 'other' box if I were given the option.

One participant reported that he makes a point of checking multiple boxes, even when told to only select one. Most participants noted having to consider their response before identifying racial categories on forms, something that monoracial individuals do not have to consider.

When asked about how race messages they have received have influenced the way they racially identify themselves, the majority of participants, nine, reported that they make conscious choices to identify as mixed or biracial. Reasons for this included wanting to accurately represent their racial identity, rather than feel pressure to choose one race over another, and not wanting to feel like they were in some way betraying one 
of their parents by not acknowledging part of their racial identity. For example, P 12 participant stated, "I think I may be more proud to check two boxes whenever I can, because I feel like, you know, just checking one, or checking 'other' is not demonstrative of what I really am.” P2 (White, Black) responded, "the idea of wanting to skew one way or another felt, would feel like a betrayal of one of my parents. So I've always been adamant about being both". Additionally, participants recognized questions about their race have been influenced by their racially ambiguous features; questions would not be posed if their racial background was more visibly apparent to others. For example, P7 (White, Black) stated,

Maybe it would have been different if I was darker, you know, or if my hair was straighter. But this is what I have, and I kind of look like a white guy with Black people hair to some people. So, there's always something that kind of needs explaining if raced is discussed and I'm there.

Three participants reported that while they view their White heritage as an important part of their identity, they make intentional choices to de-emphasize being part White. One person noted not wanting to "pass" as White as a way of challenging White privilege. P12 (White, Black) described recognizing that her experiences may be influenced by others seeing and treating her as a person of color, so this motivates her to identify with her minority heritage over her White heritage. She stated,

I feel like I have more Black experiences than white experiences, because I'm never going to be seen as like White because my skin is not White and my hair is not White. And I'm not really going to be seen as like fully Black, but... I will more readily identify as Black.

Four of the participants noted how they view race as only part of their identity, and expressed the importance of recognizing other aspects of their identity, such as gender, education and profession, and social class. Social class, in particular, was 
identified as being a more salient part of their identity than race for these participants; five others also commented on social class having an impact on their identity, but did not feel it was more salient for them than race. They noted that opportunities they have had, neighborhoods they have lived, and values held by their families were impacted by social class factors; while their racial background may intersect with their social class identity, these participant more readily identified class as a large impact on how they understand themselves. 


\section{CHAPTER FIVE}

\section{DISCUSSION}

The present study explored mixed race individuals' experiences within specific racial socialization contexts of family, friends, community, and society, to identify messages that mixed race individual have received within these contexts, as well as examine how those messages have influenced both their understandings of their mixed race identity and how they racially identify themselves. Numerous themes voiced across participants emerged within each socialization context. These included disownments/disapproval, sibling differences, and race dialogues within the context of family, seeking diversity and racial awareness in the context of friends, environmental factors, seeking diversity, and 'What are you?' questions in the context of community, and racial categorization, normativity, attractiveness, and the President Obama effect in the contexts of society. With the exception of the society context, there were no common specific messages received by participants within individual socialization contexts. Rather, shared general message themes of belonging, racial physical features, racial teasing, and racism, emerged across these contexts. For instance, participants discussed receiving general messages that communicated themes of belonging- experiences of fitting in, being an outsider, variable inclusion and exclusion in different contexts-, but there was no commonality of specific messages received that might directly communicate the degree to which mixed race individuals do, or do not, belong within various contexts. 
Across participants, commonality was found in how these messages influenced their understandings of mixed race identity, including developing cultural consciousness, interests in racial discourse, pride in mixed race identity, and awareness of mixed race privilege. While there was variability found among participants' personal racial identifications (i.e.- biracial, mixed, one race), there was consensus that messages influenced participants to make conscious decisions in identifying themselves to others as mixed, rather than feel pressure to choose one race over the other.

Participants in the present study noted having different understandings of their racial identity at various points in their lives, and generally developed a stronger sense of racial identity with age. However, contrary to processes described by stage models of mixed race identity development (i.e. Jacobs, 1992; Kerwin \& Ponterotto, 1995; Kich, 1992; Poston, 1990), there did not appear to be a common progression through stages at specific phases of life. Additionally, while participants discussed concepts identified in these models- pressure to identify with one race, 'What are you?' questions, and developing security in personal identity versus identifying according to others' expectations (Kerwin \& Ponterotto, 1995; Kich, 1992; Poston, 1990)-, grappling with such concepts were not associated with specific points in their lives. Rather, reflections upon these appeared to arise earlier or later based on individual experiences and contextual factors, and such reflections were on-going, with ebbs and flows, over time. For instance, participants discussed frequent 'What are you?' questions from childhood to the present, and having continued to evaluate their feelings about, and responses to, such questions. In contrast, stage models suggest that difficulty navigating responses to 'What are you?' questions occurs in childhood and early adolescence, and later in life having a 
secure identity and recognizing societal values on racial categorization make such questions less distressing (Kerwin \& Ponterotto, 1995; Kich, 1992).

Discrepancies between processes identified in stage models and those found in the present study may be attributed to changing social contexts over the past 20 years since these models were first researched and developed. Increased normativity of mixed race identity from continued growth of the mixed race population, may have influenced shifts in racial identity development processes. As the boundaries of race relations are less rigid than in the past, messages regarding race may be more implicit than direct, and meanings that inform racial identity concepts may be derived from interpretations of message themes received across different life contexts. Consequently, 'What are you?' questions may take on different meanings- attempts to categorize versus expressions of curiosity or interest- based on the context in which these questions are posed, and warrant additional reflection by individuals to assess the intent of the question and how they might want to respond; whereas, in the past such questions mainly served to highlight racial difference and outsider status.

The findings of the present study rather support Root's (1998) ecological model of racial identity development, which had suggested that the interaction of numerous contextual factors, inherited influences, traits, and social environments, serve as macroand micro- lenses through which individuals filter and interpret meanings that inform racial identity, and how individuals choose to identify themselves. This model argued that racial identity development among mixed race individuals is not necessarily a linear process, may instead be situational, simultaneous, and mutable over the course of one's life, and may or may not coincide with racial categories imposed by others. In support of 
Root's (1998) model, the present study found that participants' sense of racial identity and racial identification choices were informed by their experiences within different socialization contexts and how they made sense of the messages communicated within those contexts.

While Root's (1998) model is comprehensive in identifying many factors that can influence individuals' racial identity development process, this model lacks depth in explaining how meaning is derived from these factors in order to inform racial identity; it is suggested that individual traits, such as personality features and coping styles, contribute to how mixed race individuals may interpret and respond to contexts within their lives, but what is missing is clarity concerning the mechanism through which interpretations of contexts may be made. The findings of the present study suggest that racial socialization messages may serve as such a mechanism. It was found that messages regarding race were communicated directly and indirectly within different contexts of participants' lives, and participants' interpretations of these messages influenced how they made meaning of their experiences within socialization contexts to develop a sense of racial identity.

This process was, in particular, demonstrated in participants' discussions of the messages they received in various societal contexts. Participants reported receiving messages regarding the value society places on racial categorization, and interpreted that one's social standing was influenced by their racial group memberships. Their experiences across socialization contexts communicated additional messages concerning societal attitudes held about Black and Asian groups, and influenced differences in racial identity development processes for part Black and part Asian individuals. Historically, 
racial hierarchies were established due to concerns about maintaining racial purity and White dominance within society, with particular emphasis placed on upholding boundaries between White and Black individuals through laws of hypodescent and antimiscegenation (Ferber, 2004; Gallagher, 2004; McClain DaCosta, 2004; Nakashima, 1992; Spickard, 1992; Teo, 2004). In the present study, part Black participants reported experiences with overt racism, whereas part Asian participants more commonly reported experiencing microaggressions through racial teasing. Previous research has suggested, that mixed race individuals may experience varying degrees of discrimination based on the composition of their racial background, with mixed Asians receiving greater acceptance than Black mixed race individuals (Gallagher, 2004; Kerwin \& Ponterotto, 1995). This was attributed to views that Asians have "cultural characteristics (a strong work ethic, commitment to family, focus on schooling) that Whites believe (or imagine) themselves as possessing" (Gallagher, 2004, p. 60), whereas Blacks have been negatively characterized as dangerous, aggressive, and lazy (Ferber, 2004; Gallagher, 2004;

Spickard, 1992). While both groups in the present study experienced discrimination, part Black individuals were directly confronted with negative attitudes and treatment that challenged them to evaluate impacts of racism within society, and on their sense of self. For part Asian participants, it seemed that building racial awareness through education and racial discourse with other people of color, influenced later recognition of subtle racism that underlies racial teasing, and consequently prompted reflections on their racial identity. 


\section{Implications}

\section{Racial Identity Development Theory}

The findings of the present study suggest that racial identity development among mixed race individuals follows an ecological framework, in which racial socialization messages serve as a mechanism through which experiences within different socialization contexts may be interpreted, to then inform understandings of racial identity and how individuals choose to identify themselves. As noted previously, across the contexts of family, friends, community, and society, messages are communicated regarding themes of societal value placed on racial categorization, belonging, racial physical features, racism, and racial teasing. Furthermore, it appears that these messages may be interconnected, and interactions between messages and socialization contexts may underlie racial identity development processes. For instance, one's racial physical features can impact how a mixed race person may be perceived and treated by others, potentially contributing to encounters with racism or racial teasing, and consequently influence their sense of belonging within given contexts. Additionally, individual traits or characteristics, can influence the interpretations and meanings derived from interactions between socialization contexts and messages. As such, the ways in which one understands and responds to these interactions may vary from person to person, thereby yielding differences in racial identity conceptions and identification. Despite the possibility of such differences, the present study found that common influences of messages on racial identity were the development of cultural consciousness, interests in racial discourse, and awareness of mixed race privilege. Thus, racial identity theories 
regarding mixed race individuals should include considerations of interactions between individual and various contextual factors from an ecological perspective.

\section{Research}

Contrary to previous research, which has identified family as the primary source of racial socialization messages to inform individuals about cultural history and values, prepare them for potential experiences of prejudice in regards to race, and provide guidance for coping with discrimination (Brody et al., 2006; Bynum et al., 2007; Fischer \& Shaw, 1999; Gillem, Cohn, \& Throne, 2001; Hughes et al., 2006; Kerwin et al., 1993; Kerwin \& Ponterotto, 1995; McClain DaCosta, 2004; Miville et al., 2005; O’Brien Caughy, 2004; Phillips Smith, \& Johnson, 2009; Robbins et al., 2007; Rodriguez, Umaña-Taylor, Smalls, 2010; Root, 1998; Stevenson \& Renard, 1993; White-Johnson et al., 2010; Wills et al., 2007), only five of the 12 participants reported that issues of race were directly addressed within their families. As such, it appeared that racial socialization messages were received more implicitly across different contexts in their lives. For instance, rather than receiving preparation from family on societal conceptions of beauty based on race, comments made about having "good hair" or "good skin tone" and the use of racially ambiguous models in advertisements communicated the message to participants that society views ambiguous or Europeanized physical features as attractive. It was unclear what may have contributed to the lack of direct conversations and guidance on racial issues within participants' families. Gillem et al. (2001) had suggested that among interracial couples in which one parent is White, the parent of color more frequently addresses racial issues with their mixed race child than the White parent due to greater recognition of societal value placed on race. In the present study, however, 
there was no difference in the degree to which racial issues were addressed by either parent. Future research may more closely explore dynamics within interracial families, and how parents of mixed race children view and approach racial socialization with their children.

\section{Clinical Practice}

Culturally competent clinical practice in working with mixed race individuals may be informed by the findings of the present study. With messages received regarding value placed on having a clearly identifiable race, mixed race clients may grapple with questions of belonging, how their physical features impact how they are perceived and treated by others, and how to define themselves racially versus definitions imposed by others; when individuals are asked so frequently, 'What are you?', they are challenged to reflect upon their identity in order to answer that question to themselves and to otherswho they are, how they are seen, and how well they fit into categories of race. Navigating such issues may influence difficult emotions, and have a bearing on individuals' general well being, emotional functioning, and their ability to cope with experiences, such as encounters with racism or racial teasing. Given the current finding that family was not the primary source of imparting cultural knowledge, nor preparation and guidance on racial issues and exposure to racism, it may helpful to examine what factors have helped individuals presenting to counseling, to develop a sense of their racial identity. Therefore, it may be beneficial for clinicians to assess racial identity development processes through clients' experiences within the contexts of family, friends, community, and society, the racial socialization messages communicated within those contexts, and explore the ways 
in which clients derive and interpret meaning from messages received, to inform conceptions of their racial identity and how they racially identify themselves.

The findings of the present study may additionally be beneficial to consider in working with interracial couples and families. The prevalence of disownments and disapproval from extended family was surprising given that all of the participants were born after the Civil Rights Movement, when interracial relationships were increasingly common, and marriages of interracial couples became legal in all states. This suggested that despite broader social acceptance of racial diversity, the value of maintaining divisions between racial groups still remains and can pose challenges in family relationships. Individuals who have been disowned by their family for being in an interracial relationship, may struggle with symptoms of grief related to the loss of family connection. Furthermore, such losses may contribute to resentment and tensions within couples and families for having influenced the dissolution of relationships with extended family. Additionally, while few participants in the present were directly impacted by disownments, as most families eventually reconciled, such ruptures in family relationships may contribute to how mixed race children understand their racial identity through lesser connection with part of their racial heritage in terms of knowledge that can be imparted by extended family.

\section{Prevention}

In connection with family processes, the present study may pose implications for prevention efforts. It was found that participants whose families discussed racial issues directly tended to have greater racial awareness, and among those with families that did not discuss race, most sought opportunities to build racial awareness to better understand 
themselves and others. To prevent emotional difficulties among mixed race youth and increase potential of developing a healthy racial identity, it may be beneficial for interracial couples to develop comfort with engaging in racial dialogues with their children, and with each other. Counseling and/or psychoeducational workshops may be helpful in openly exploring racial views and values, identify areas of discomfort in regards to racial issues, and learning strategies to engage in racial dialogues in a productive and healthy manner. This can better prepare parents to cope with and address common experiences and challenges of mixed race children.

\section{Limitations and Future Directions}

The findings of the present study may be strengthened by replication with a larger sample. Research on grounded theory has suggested that a sample should be sufficiently large enough for saturation to occur. The present study showed some saturation to permit common themes to emerge across interviews, but did not yield sufficient saturation that additional interviews could not strengthen the results. Additionally, in selecting participants across different mixed race heritages, the researcher was able to identify themes that may be common to a wider range of mixed race individuals, than may have been the case in focusing on specific racial mixtures. Granted, there may be differences between mixed race groups, in the racial socialization processes and types of messages communicated and received. This was highlighted in that no Asian-White mixed participants reported receiving direct communication about racial issues from family, compared to four Black-White participants, and one multiracial Black-Asian-White participant. While individual factors among participants may have contributed to this 
finding, it may be worth further examination to explore racial socialization processes across mixed race groups.

The majority of the participants in this study were highly educated, and had taken coursework, or had educational interests, in race and multicultural issues. As such, the amount of complexity to which participants were able to speak about race issues and their identity development processes may have been influenced by their educational experiences. Additionally, interest in engaging in racial discourse was found to be common among over half of participants. While this may be connected to racial socialization and identity development processes, interests in such discourse may also stem from pursuits of higher education, particularly in multicultural coursework where racial dialogues are emphasized. Future research should include a more varied sample in order to control for factors such as level of education.

The average age of the participants may be a potential limitation of this study. Many spoke to society's growing acceptance of racial diversity and of mixed race individuals. As such, younger generations may receive different messages about mixed race identity than those of older generations. As interracial relationships are becoming increasingly common, and the population of mixed race individuals continues to grow, the ways in which mixed race identity is understood and discussed may be changing. Further exploration of potential shifts in racial socialization messages may have implications for racial identity development among a generation of young people who are growing up in contexts in which they may be considered less of an anomaly than in previous generations. In the present study, there were no significant differences in the experiences, nor messages received between participants who were 18 and 20, and those 
whom were in their late 20 s and up. It is difficult to determine if this lack of difference may be attributable to the younger participants' education in race issues, more so than generational factors. It will be valuable to conduct future research with younger mixed race individuals, to examine potential generational differences.

\section{Conclusion}

The present study aimed to examine what messages mixed race individuals receive regarding race and racial identity, and how those messages become incorporated into one's understanding of their racial identity and influence racial identification. As society becomes increasingly accepting of racial diversity and mixed race individuals, remnants of historical contexts that placed value on racial categorization, hierarchies, and divisions, may continue to underlie the types of experiences and messages one receives regarding what it means to be mixed. Therefore, in order to understand mixed race identity development processes, it is important to take contextual factors, and messages communicated within those contexts, into account. While previous research on mixed race individuals has suggested that messages regarding race are communicated within different contexts of their lives, none have addressed how messages are communicated, nor what types of messages are communicated. Additionally, despite being an important construct related to racial identity development, no previous research has examined racial socialization processes of mixed race individuals. In an effort to address these gaps in the

literature, the present study explored mixed race individuals' experiences within specific racial socialization contexts, and identified common message themes that individuals receive, derive meaning from, and informs their conceptions of their racial identity and racial identification choices. The current findings provide valuable contributions to 
understandings of mixed race identity development theories, research, and clinical practice with this population. 
APPENDIX A

DEMOGRAPHIC FORM 
1. Age

2. Gender: Male Female

3. Racial Identification (select all that apply):

White (Caucasian, European American)

Black (African American)

Asian or Pacific Islander

Hispanic (Latino/a)

Native American

Other (please specify)

4. Maternal Racial Identification (select all that apply):

White (Caucasian, European American)

Black (African American)

Asian or Pacific Islander

Hispanic (Latino/a)

Native American

Other (please specify)

5. Paternal Racial Identification (select all that apply):

White (Caucasian, European American)

Black (African American)

Asian or Pacific Islander

Hispanic (Latino/a)

Native American

Other (please specify)

6. Generations in the U.S. (check most applicable one)

I was born outside the U.S. (e.g., Mexico) and moved to the U.S.

I was born in the U.S. but both parent(s) immigrated.

One parent and I were born in the U.S. (other parent immigrated).

Both parents and I were born in the U.S.

Grandparents, parents, and I were born in the U.S.

Great-grandparents and beyond were born in the U.S.

7. If you were born outside the U.S. (e.g., China) and moved to the U.S., how old were you when you moved to the U.S.? 
8. How would you describe your social class?

lower class

lower-middle class

middle class

upper-middle class

upper class

9. Highest level of education completed:

High School

Associates

Bachelors

Masters

Doctorate

Other (please specify) 
APPENDIX B

INTERVIEW QUESTIONS 


\section{Identity Questions:}

*How do you racially identify yourself?

*When asked to specify your racial background (such as on official forms or documents), how do you respond? (Do you select more than one racial category? If you are only allowed to select one racial category, what do you select?)

*When asked "What are you?", how do you respond?

*Do you racially identify yourself differently in different contexts? If so, in what contexts might you identify differently and how do you identify yourself in those contexts?

\section{Race Questions:}

*What is your understanding the concept of race? (i.e- is race important, how does race operate in society, what are the advantages/disadvantages of different racial groups, etc.) *What does it mean to you to have a mixed racial background?

\section{Race Message Questions:}

*How has your racial background been discussed or understood in your family? (What messages, if any, have you received about your race from your family? Is having a mixed race background understood in your family as good, bad, or neutral?)

*How has your racial background been discussed or understood amongst your friends and/or peers? (What messages, if any, have you received about your race from your friends and/or peers? Is having a mixed race background understood amongst your friends and peers as good, bad, or neutral?)

* What was the racial make-up of your group of friends while growing up? What is the racial make-up of your group of friends currently? 
* Have you had access to opportunities to make friends with people of diverse backgrounds?

*How has your racial background been discussed or understood in your community? (What messages, if any, have you received about your race from members of your community? Is having a mixed race background understood in your community as good, bad, or neutral?)

* What is the racial make-up of your community?

*How is racial background viewed by society? (What messages, if any, have you received about your race from society in general? Is having a mixed race background understood in society as good, bad, or neutral?)

*How do you think these messages have influenced you?

*How have these messages influenced how you understand your own race?

*How have these messages influenced how you identify yourself racially?

\section{General Questions:}

*What other factors do you feel have influenced your understanding of race and your racial identity?

*Is there anything that we have not discussed, or that was not asked about, that you feel is important to your experience/and or identity as a mixed race individual? 


\section{REFERENCE LIST}

Ahnallen, J., Suyemoto, K., \& Carter, A. (2006) Relationship between physical appearance, sense of belonging and exclusion, and racial/ethnic selfidentification among multiracial Japanese European Americans. Cultural Diversity and Ethnic Minority Psychology, 12, 673-686.

Brown, U. (1995). Black/White interracial young adults: Quest for racial identity. American Journal of Orthopsychiatrics, 65, 125-130.

Brody, G.H., McBride Murry, V., Gerrard, M., Gibbons, F.X., McNair, L., Brown, A.C., Wills, T.A., Molgaard, V., Spoth, R.L., Luo, Z., \& Chen, Y.F. (2006). The strong African American families program: Prevention of youths' high-risk behavior and a test of a model of change. Journal of Family Psychology, 20, 1-11.

Collins, J. (2000). Biracial Japanese American identity: An evolving process. Cultural Diversity \& Ethnic Minority Psychology, 6, 115-133.

Cross, W. (1971). The Negro to Black conversion experience: Towards a psychology of Black Liberation. Black World, 20, 273-276.

Dalmage, H.M. (2004). Introduction. In H.M. Dalmage (Ed.) The politics of multiracialism: Challenging racial thinking. (pp. 1-16). Albany, NY: State University of New York.

Edwards, L.M \& Teramoto Pedrotti, J. (2008). A content and methodological review of articles concerning multiracial issues in six major counseling journals. Journal of Counseling Psychology, 55, 411-418.

Ferber, A.L. (2004). Defending the creation of whiteness: White supremacy and the threat of interracial sexuality. In H.M. Dalmage (Ed.) The politics of multiracialism: Challenging racial thinking. (pp. 43-57). Albany, NY: State University of New York.

Fisher, A.R. \& Shaw, C.M. (1999). African Americans' mental health and perceptions of racist discrimination: The moderating effects of racial socialization experiences and self-esteem. Journal of Counseling Psychology, 46, 395-407 
Gallagher, C.A. (2004). Racial redistricting: expanding the boundaries of whiteness. In H.M. Dalmage (Ed.) The politics of multiracialism: Challenging racial thinking. (pp. 59-76). Albany, NY: State University of New York

Gillem, A., Cohn, L., \& Thorne, C. (2001). Black identity in biracial Black/White people: A comparison of Jacqueline who refuses to be exclusively Black and Adolphus who wishes he were. Cultural Diversity \& Ethnic Minority Psychology, 7, 182196.

Heppner, P.P., Wampold, B.E., \& Kivilghan, D.M. (2008). Research Design In Counseling. $3^{\text {rd }}$ ed. United States: Thomson Brooks/Cole.

Hill, C.E., Knox, S., Thompson, B.G., Williams, E.N., Hess, S.A., \& Ladany, N. (2005). Consensual qualitative research: An update. Journal of Counseling Psychology, 52, 196-205.

Hill, C.E., Thompson, B.J., \& Williams, E.N. (1997). A guide to conducting consensual qualitative research. The Counseling Psychologist, 25, 517-572.

Hughs, D., Rodriguez, J., Smith, E.P., Johnson, D.J., Stevenson, H.C., Spicer, P. (2006). Parents' ethnic-racial socialization of practices: a review of research and directions for the future. Developmental Psychology, 42, 747-770.

Hughs, D., Witherspoon, D., Rivas-Drake, D., West-Bey, N. (2009). Received ethnicracial socialization messages on youths' academic and behavior outcomes: Examining the mediating role of ethnic identity and self esteem. Cultural Diversity and Ethnic Minority Psychology, 15, 112-124.

Jacobs, J. (1992). Identity development in biracial children. In M.P.P. Root (Ed.) Racially mixed people in America (pp. 190-206). Newbury Park, Ca: Sage Publications.

Kerwin, C. \& Ponterotto, J. (1995). Biracial identity development: Theory and research. In J. Ponterotto, J.M. Casas, L.A. Suzuki, \& C.M. Alexander (Eds.), Handbook of multicultural counseling (pp.199-217). Thousand Oaks, Ca: Sage Publications.

Kerwin, C., Ponterotto, J, Jackson, B., \& Harris, A. (1993). Racial identity in biracial children: A qualitative investigation. Journal of Counseling Psychology, 40, 221231.

Kich, G. (1992). The developmental process of asserting biracial, bicultural identity. In M.P.P. Root (Ed.) Racially mixed people in America (pp. 280-317). Newbury Park, Ca: Sage Publications. 
Lalonde, R.N., Jones, J.M., Stroink, M.L. (2008). Racial identity, racial attitudes, and race socialization among black Canadian parents. Canadian Journal of Behavioral Sciences, 40, 129-139.

Merriam, S.B. (2009). Qualitative research: A guide to design and implementation. San Francisco, Ca: Jossy-Bass A Wiley Imprint.

McClain DaCosta, K. (2004). All in the family: The familial roots of racial division. In H.M. Dalmage (Ed.) The politics of multiracialism: Challenging racial thinking. (pp. 19-41). Albany, NY: State University of New York.

Miville, M., Constantine, M., Baysden, M., \& So-Lloyd, G. (2005). Chameleon changes: An exploration of racial identity themes of multiracial people. Journal of Counseling Psychology, 52, 507-516.

Nakashima, C.L. (1992). An invisible monster: The creation and denial of mixed people in America (pp. 162-178). In M.P.P. Root (Ed.) Racially mixed people in America. Newbury Park, Ca: Sage Publications.

O’Brien Caughy, M., O’Campo, P.J., Muntaner, C. (2004). Experiences of racism among African American parents and the mental health of preschool-aged children. American Journal of Public Health, 94, 2118-2124.

Patria, M. (2007). Groundbreaking interracial marriage. ABC News. Retrieved from: http://abcnews.go.com/US/story?id=3277875

Robbins, M.S., Szapocznik, J., Mayorga, C.C., Dillon, F.R., Burns, M., \& Feaster, D. (2007). The impact of family functioning on family racial socialization processes. Cultural Diversity and Ethnic Minority Psychology, 13, 313-320.

Rodriguez, J., Phillips Smith, E., Umana-Taylor, A., \& Johnson, D. (2009). Cultural processes in parenting and youth outcomes: examining a model of racial-ethnic socialization and identity in diverse populations. Cultural Diversity and Ethnic Minority Psychology, 15, 106-111.

Root, M. (1992). Within, between, and beyond race. In M.P.P. Root (Ed.) Racially mixed people in America (pp. 3-11). Newbury Park, Ca: Sage Publications.

Root, M. (1998). Experiences and processes affecting racial identity development: Preliminary results from the Biracial Sibling Project. Cultural Diversity \& Mental Health, 4, 237-247.

Root, M. (2002). Methodological issues in multiracial research. In G. Nagayama- Hall \& S. Okazaki (Eds). Asian American psychology: The science of lives in context (pp. 171-193). Washington, DC, US: American Psychological Association. 
Seaton, E.K., Yip, T., Morgan-Lopez, A., \& Sellers, R.M., Racial discrimination and racial socialization as predictors of African Americans adolescents' racial identity development using latent transition analysis. Developmental Psychology, 48, 448458.

Shih, M., Bonam, C., Sanchez, D., \& Peck, C. (2007). The social construction of race: Biracial identity and vulnerability to stereotypes. Cultural Diversity \& Ethnic Minority Psychology, 13, 125-133.

Smalls, C. (2010). Effects of mothers' racial socialization and relationship quality on African American youths' school engagement: A profile approach. Cultural Diversity and Ethnic Minority Psychology, 16, 476-484.

Smith Bynum, M., Burton, E.T., \& Best, C. (2007). Racism experiences and psychological functioning in African American college freshman: Is racial socialization a buffer? Cultural Diversity and Ethnic Minority Psychology, 13, 6471.

Spickard, P. (1992). The illogic of American racial categories. In M. P. P. Root (Ed.) Racially mixed people in America (pp. 12-23). Newbury Park, Ca: Sage Publications.

Stevenson, H.C. \& Arrington, E.G. (2009). Racial/ethnic socialization mediates perceived racism and the racial identity of African American Adolescents. Cultural Diversity and Ethnic Minority Psychology, 15, 125-136.

Stevenson, H.C. \& Renard, G. (1993). Trusting ole' wise owls: Therapeutic use of cultural strengths in African-American families. Professional Psychology: Research and Practice, 24, 433-442.

Stonequist, E. (1937). The marginal man: A study in personality and culture conflict. New York: Russell \& Russell.

Sue, S., \& Sue, D.W. (1971). Chinese American personality and mental health. Amerasian Journal, 1, 36-49.

Suzuki-Crumly, J. \& Hyers, L. (2004). The relationship among ethnic identity, psychological well-being, and intergroup competence: An investigation of two biracial Groups. Cultural Diversity \& Ethnic Minority Psychology, 10, 137-150.

Teo, T. (2004). The historical problematization of "mixed race" in psychological and human scientific discourses. In A. S. Winston (Ed). Defining difference: Race and racism in the history of psychology (pp. 79-108). Washington, DC, US: American Psychological Association. 
Thompson, C.P., Anderson, L.P., \& Bakeman, R.A. (2000). Effects of racial socialization and racial identity on acculturative stress in African American college students. Cultural Diversity and Ethnic Minority Psychology, 6, 196-210.

Wardle, F. (1996). Children of mixed-race unions should be raised biracially. In D. Bender, B. Leone, \& B. Szumski (Eds.). Interracial America: Opposing viewpoints (pp. 197-203). San Diego, Ca: Greenhaven Press.

White-Johnson, R.L., Ford, K.R., Sellers, R.M. (2010). Parental racial socialization profiles: Association with demographic factors, racial discrimination, childhood socialization, and racial identity. Cultural Diversity and Ethnic Minority Psychology, 16, 237-247.

Wills, T.A., McBride Murry, V., Brody, G.H.,Gibbons, F.X., Gerrard, M., Walker, C., \& Ainette, M.G. (2007). Ethnic pride and self control related to protective risk factors: Test of the theoretical model for the strong African American family program. Health Psychology, 26, 50-59. 
VITA

Jennifer Moulton was raised in Temecula, CA. She earned a Bachelor's of Science degree in Applied Psychology from New York University in 2005. She then Teacher's College at Columbia University, where she earned a Master's of Education in Psychological Counseling, in 2009.

Throughout her studies at Loyola University Chicago, Jennifer Moulton received training as mental health counselor serving diverse populations in the Chicagoland area. She also presented on mental health topics to professional and community audiences, served for one year as Vice President of the Doctoral Advisory Committee in the Department of Counseling Psychology, and taught an undergraduate course on Identity and Pluralism at Loyola University Chicago.

Currently, Jennifer Moulton is working as a Postdoctoral Fellow at Counseling and Consultation Services at the University of Wisconsin, Madison 